\title{
International study on energy end-use data among industrial SMEs (small and medium- sized enterprises) and energy end-use efficiency improvement opportunities
}

Patrik Thollander, Svetlana Paramonova, Erwin Cornelis, Osamu Kimura, Andrea Trianni, Magnus Karlsson, Enrico Cagno, Ines Morales and Juan Pablo Jimenez Navarro

\section{Linköping University Post Print}

\section{Tweet}

N.B.: When citing this work, cite the original article.

Original Publication:

Patrik Thollander, Svetlana Paramonova, Erwin Cornelis, Osamu Kimura, Andrea Trianni, Magnus Karlsson, Enrico Cagno, Ines Morales and Juan Pablo Jimenez Navarro, International study on energy end-use data among industrial SMEs (small and medium-sized enterprises) and energy end-use efficiency improvement opportunities, 2015, Journal of Cleaner Production, (104), 282-296.

http://dx.doi.org/10.1016/j.jclepro.2015.04.073

Copyright: Elsevier

http://www.elsevier.com/

Postprint available at: Linköping University Electronic Press

http://urn.kb.se/resolve?urn=urn:nbn:se:liu:diva-120435 
International study on energy end-use data among industrial SMEs and energy end-use efficiency improvement opportunities

\author{
Patrik Thollander*, \\ Department of Management and Engineering, Linköping University, SE-581 83 \\ Linköping, Sweden, patrik.thollander@liu.se \\ Svetlana Paramonova, \\ Department of Management and Engineering, Linköping University, SE-581 83 \\ Linköping, Sweden, svetlana.paramonova@liu.se
}

\author{
Erwin Cornelis, \\ VITO NV, Boeretang 200, 2400 \\ MOL, Belgium, erwin.cornelis@ vito.be
}

Osamu Kimura,

Socio-economic Research Center, Central Research Institute of Electric Power Industry 1-6-1

Otemachi Chiyoda-ku, 100-8126

TOKYO, Japan, o-kimura@criepi.denken.or.jp

Andrea Trianni,

Politecnico di Milano, Dept. Management, Economics and Industrial Engineering,

Piazza Leonardo da Vinci 32 - 20133

Milan, Italy, andrea.trianni@polimi.it

Magnus Karlsson, 
Department of Management and Engineering, Linköping University, SE-581 83

Linköping, Sweden, magnus.karlsson@ liu.se

\title{
Enrico Cagno,
}

Politecnico di Milano, Dept. Management, Economics and Industrial Engineering,

Piazza Leonardo da Vinci 32 - 20133

Milan, Italy, enrico.cagno@polimi.it

Inés Morales,

IAT (Instituto Andaluz de Tecnología), Marie Curie, 4. local D2, 29590

MÁLAGA, Spain, imorales@iat.es

Juan Pablo Jiménez Navarro,

IAT (Instituto Andaluz de Tecnología), Marie Curie, 4. local D2, 29590

MÁLAGA, Spain, jpjimenez@iat.es

*corresponding author fax +4613281788 office +4613285745

\begin{abstract}
The industrial sector is important to study in terms of improved energy efficiency, being one of the major energy-using sectors and responsible for a major share of $\mathrm{CO}_{2}$ emissions. The energy end-use (EEU) in the industrial sector is complex in general as processes are intertwined and interrelated. Moreover, bottom-up data of EEU on an aggregated level is scarce. Data for total energy supply like electricity, oil, coal, and natural gas exists but bottom-up data of what processes these energy carriers are used in, and moreover, where the major potential for implementation of energy efficiency measures (EEMs) exists, is less prevalent.
\end{abstract}


This holds in particular for industrial small and medium-sized enterprises (SMEs). This makes policy formulation and design for industry a great challenge. Knowledge on where and how energy is used, as well as where opportunities for improvement exist, may provide good support for developing the most effective policies. Therefore, the aim of this study has been to present and compare available bottom-up energy data for industrial SMEs in four countries, namely Belgium, Italy, Japan and Sweden. Results show that the existence and quality of bottom-up EEU data differs largely between the countries and the development of a general taxonomy of structuring EEU data as well as EEMs is needed. Without the development of such a general taxonomy, the deployment level of EEMs and carbon dioxide emission reductions is unlikely to ever reach its full potential as knowledge is missing on how large the potential is, in which processes the major potential is found, how far industry has reached in terms of deployment levels, and in which areas future energy policies are needed. In conclusion, this paper of EEU and EEM in industrial SMEs addresses the high importance of future research in creating a harmonized data categorization, as this will greatly support the transition towards sustainable industrial energy systems.

\section{Introduction}

Energy use is growing fast, due to the larger role of emerging economies based primarily on fossil fuel technologies (IEA, 2013). The industrial sector is crucial as it is a major energy user, and a relevant share is used by many industrial small and medium-sized enterprises $\left(\mathrm{SMEs}^{1}\right)$. The industrial energy use among industrial SMEs is $25 \%$ in Sweden and Belgium, while in Japan industrial SMEs give rise to $11 \%$ of industry-related carbon dioxide emissions (Thollander et al., 2014). Also, industrial SMEs often have a larger relative energy efficiency

\footnotetext{
${ }^{1}$ The European Commission defines an SME as a company with 10 to 250 employees and a turnover of 2 to 50 million euros/year or a balance sheet not more than 43 million euros/year (EC, 2003a).
} 
potential than energy-intensive industry due e.g. too few resources put into energy management (EC, 2007; Shipley, 2001). Consequently, much greater attention should be paid to the world of SMEs, and the approach is now shifting, for example within the EU, from addressing a few large, energy-intensive users to many small and medium-sized users, observing that, with current trends, only half of the targeted $20 \%$ energy reduction will be achieved (European Council, 2012).

Furthermore, it is clear that improved energy efficiency can bring many benefits contributing to fully sustainable industrial competitiveness. Research here has shown that implementing energy efficiency measures $(E E M s)^{2}$ has effective benefits, e.g. in production operations (Pye and McKane, 2000; Worrell et al., 2003), operations and maintenance (Lung et al., 2005), as well as working and indoor environment (Mills and Rosenfeld, 1996). Additionally, as shown by IEA, benefits can be experienced at different levels, from industry to society as a whole (IEA, 2014). Therefore improved energy efficiency is strategic for industrial competitiveness (Cooremans, 2011), and international as well as domestic and local policies should be properly shaped in this direction.

Literature has indeed shown that, without a clear understanding of the existing difficulties, policies may be ineffective (Thollander et al., 2012). In fact, focusing on recent studies on barriers to industrial energy efficiency, technological issues have emerged in addition to economic issues (Rohdin et al., 2007), as well as lack of knowledge, by final users, of adequate energy-efficient technologies (Sardianou, 2008). Moreover, recent research has pointed out the relevance of information-related barriers (Trianni and Cagno, 2012; Kostka et al., 2013). Additionally, authors have found the lack of information about energy end-use (EEU) patterns (Schleich and Gruber, 2008) a major barrier to investing in new and more efficient technologies.

\footnotetext{
${ }^{2}$ EEM is defined as in EC (2006) as: An increase in energy end-use efficiency as a result of technological, behaviouralbehavioral and/or economic changes.
} 
Bottom-up data about the performance of EEMs are thus required. Without a common basis for the categorization of data of EEMs as well as its potential for deployment and industrial EEU, comparisons are difficult. Some work is currently being developed about EEM classification (e.g. Fleiter et al., 2012; Trianni et al., 2014), but in general, contributions are scarce. EEU in the industrial sector is complex in general as processes are intertwined and interrelated (Westling, 2000). Bottom-up data of where energy is used on an aggregated level is scarce. Data for total energy supply like electricity, oil, coal, and natural gas exists, but data of what processes these energy carriers are used in, and the potential for improvements, is less prevalent. This is even more critical for cross-cutting technologies or support processes that, being incorrectly considered less relevant than the main production systems, are widely overlooked.

Therefore, the aim of this study has been to present and compare available bottom-up energy data for industrial SMEs in four countries: Belgium, Italy, Japan and Sweden.

The paper provides novel insight into where energy is used among the different production as well as support processes, and where the technical energy efficiency potential is most evident. Moreover, it provides clear evidence of existing institutional barriers and challenges that need to be removed and overcome, in relation to EEU and EEM data on an aggregated level for industrial SMEs. The paper is structured as follows. First, a review of the literature on categorization of EEU and EEMs and potentials is presented. Second, the method of data collection is described, followed by the result section presenting the findings of the study. Finally, major findings and their implications are addressed in a concluding discussion chapter.

\section{Background on characterization of EEU data and EEMs}

\subsection{The concept of unit processes}

Industrial EEU data and EEMs may be categorized in different ways. These differences may appear between countries but also within each country. Most often the categorization is 
based on the unit process concept. This concept comprises division of EEU into smaller constituents, depending on the aim of the industrial process (Söderström, 1996). Production processes are constituent steps for manufacturing different goods (disintegrating, molding) and support processes are those which are necessary to maintain manufacturing activities but which do not result in manufacturing of goods as such (ventilation, heating). Söderström (1996)'s categorization was updated and presented by Thollander et al. (2012), where the production processes were divided into eleven categories and support processes into 21 categories:

\section{Production processes:}

- Disintegrating

- Mixing

- Disjointing

- Jointing

- Coating

- Molding

- Heating

- Melting

- Drying

- Cooling/freezing

- Packing

\section{Support processes:}

- Lightning

- Compressed air

- Ventilation

- Pumping

- Space heating

- Tap water heating

- Internal transport

- Steam system

- Administration

- Cooling

\subsection{Categorization of EEU data}

The literature review has revealed that several cases use the division of industrial EEU data into production and support processes. Thus, for example, a tool for an energy audit of a food industry in the United Kingdom (Salva et al., 2013) implements this terminology and a case study of the adaptation of eleven Swedish industries to deregulation of the electricity market (Trygg \& Karlsson, 2005) uses division into production and support processes. For evaluation 
of the "Highland Project" (an energy audit program in Sweden), unit processes are divided into generic and support processes (Thollander et al., 2007). Another definition of support processes (auxiliary processes) is also used to describe the processes not used for production of main products in a case energy audit of a Chinese glass company (Li Yingjian et al., 2010). Some articles mention only production processes, for example, an energy audit of the pyroprocessing unit of a cement plant in Nigeria (Kabir et al., 2010). There can also be a categorization which does not distinguish between production and support processes. One example is energy audit of cotton gin factories in USA (Funk \& Hardin, 2012). This categorization is based on sector-specific energy-using processes. However, these processes were not named as production processes (Funk \& Hardin, 2012). Differences in categorization can appear due to differences in objectives for different studies, e.g. Trygg and Karlsson (2005) had an aim of studying the potential for electricity improvements due to the deregulation of the European electricity market, while Thollander et al. (2012) presented the structure for a general industrial energy audit software. However, for all above cited papers except for the case study of industries' adaptation to deregulation of the electricity market and Thollander et al. (2012), different EEU process categories were used in order to determine where the EEU takes place inside the industries.

\subsection{Categorization of EEM data}

The abovementioned categorizations of industrial EEU data based on the concept of unit processes may also apply to categorization of EEMs. The Swedish set of EEM data called DEFRAM is based on data from the Swedish LTA program for improving energy efficiency in energy intensive industry (PFE), and the Swedish Energy Audit Program, using a production-support unit processes categorization (disjointing, mixing, pumping, ventilation, heating, etc.). 
In addition, the largest national set of EEM data today is the Industrial Assessment Center (IAC), which is based on previously conducted energy audits (Muller \& Kasten, 2007). Using a classification of 900 standardized measures named ARC (Assessment Recommendation Codes), a structured way of categorizing EEM data is made available. The EEMs are combined under the category "Energy management" with such subcategories as combustion systems, thermal systems, electrical power, motor systems, etc. Each subcategory is further divided into different improvement areas. For example, the subcategory "Motor systems" includes such improvement areas as motors, air compressors, and other equipment. In DEFRAM, a key has been developed which transforms the IAC's ARC code to fit the unit process categorization approach.

EEMs may also be categorized using a more general approach. Fleiter et al. (2012) propose a classification scheme for the different EEMs that are found in a study. This scheme includes twelve EEM characteristics such as internal rate of return, distance to core business and transaction cost, elaborated under three overall areas: relative advantage, technical context and informational context. The characteristics are further divided into attributes to find out the overall possible adoption rate of the specific EEM. Trianni et al. (2014) introduce a framework to characterize EEMs that is more directed towards decisions on-site than decisions regarding policy measures, which is the scheme that Fleiter et al. (2012) tend to emphasize. Trianni et al. (2014) propose instead a characterization framework applied to the EEMs in selected cross-cutting technologies including characteristics such as economic, energy, environmental production-related and implementation-related. These characteristics are then further divided into attributes, like payback time, emissions reduction and productivity.

Classification schemes for EEMs, such as proposed by Fleiter et al. (2012) and Trianni et al. (2014), are located on a higher aggregation level and are based on, and dependent on, divisions or characterizations on a lower aggregation level, such as the unit process concept or the 
ARC codes. There is no generally accepted taxonomy for categorizing industrial EEU data and EEMs.

There are a number of different approaches to the categorization of data, and there have been several European initiatives, such as the Intelligent Energy Europe project's Foundry Bench, BESS, and the European Eco Design Directive. However, there are no scientific publications on this, for which reason these are not explicitly covered in the scientific literature review.

\section{Research Method}

\subsection{Countries chosen for analysis}

Regarding the collection of bottom-up data on EEU and EEMs, four countries have been included in this study: Belgium, Italy, Japan, and Sweden. The reason for the choice of these four countries was that they are part of an international research project within the IEA (International Energy Agency) IETS (Industrial Energy Technologies and Systems) under Annex XVI, Energy Efficiency in SMEs. In addition, all four countries have a large industrial sector.

The data presented in this paper is to the authors' awareness the most highly representative data that has been publicly available in the studied countries in regard to industrial SMEs during 2013-2014. Due to the aforementioned lack of taxonomy for categorizing industrial EEU data and EEMs, and the large variety of categorizations between countries, the project, initially planned to stick with one common taxonomy, instead rely on each country's own data categorization. Due to the challenge of setting common Key Performance Indicators (KPIs) for various processes in industry, an emphasis was to classify the process-specific EEU. 


\subsection{Data collection}

The data from the respective country for industrial SMEs was collected from bottom-up energy audit programs (Belgium, Italy and Sweden) from years when such was available, and from publicly available data (Japan). For Belgium and Sweden, the data was gathered from the national energy agencies, stemming from governmental industrial energy policy programs. For Italy, the data was collected from research-oriented industrial energy audits supported by governmental energy policy programs, and for Japan the data was collected from trade organizations, as no national data from e.g. energy audit programs was available. Only the data from Italy distinguishes between energy-intensive and non-energy-intensive companies, while Swedish and Japanese data do not provide such distinction. Moreover, two datasets were available for Belgium. The first included energy-intensive medium-sized industrial companies and does not emphasize EEU, although details on the EEMs are provided. The second data set was from conducted energy audits in non-energy-intensive SMEs. That dataset has a sectoral breakdown of the electrical EEU, but not of the EEMs.

Japanese EEU and EEM data collected in this study correspond to the individual industrial sites of the SMEs and thus do not include buildings in a different location, e.g. a company's headquarters in a city center or sales offices. Such data, however, include accompanying administrative buildings within the industrial sites. This is relevant for Swedish data as well. The Italian data also encompass whole companies, including administrative buildings such as offices, etc.

Energy-saving potential for Japan corresponds to techno-economical potential because the data on energy-saving potential are based on bottom-up energy audits, whose primary objective is to propose cost-effective measures that private firms might want to adopt. Criteria for economic efficiency depend on each program, and in some instances, on each auditor or audited firm. The same applies to Sweden. Usually EEMs with a payback period of less than 
three to five is preferred, but often EEMs with slightly less than eight years are also included in recommendations.

The data for Italy have also been assessed after having conducted on-site energy audits. The physical units (kWh/year) refer to a technical estimation of the energy potential that could be saved through application of an energy efficiency measure with respect to the total actual annual EEU. In some cases it was also possible to complement the information provided about energy efficiency potential with additional estimation about the economic profitability of a possible investment through classical cash-flow analysis techniques (net present value for measures requiring large investments, simple payback time for measures with immediate returns). In fact, considering the different contexts of investigation (countries, sectors), with different discount rates according to firms' characteristics, economic potential would be necessarily biased and could provide misleading information.

\subsection{Data analysis}

Even taking into account the differences in the data from the different countries and that a general taxonomy of categorizing such data is lacking, and therefore that the information may not be fully homogeneous, it is highly relevant to present the data, as large international sets of bottom-up data from EEU and EEMs have not been previously presented for industrial SMEs.

Despite the difficulty in categorizing data bottom-up from EEU and EEMs, the study aimed to differentiate "production processes" from "support processes" for several reasons, e.g. the production processes are often monitored and carefully operated, but difficult to categorize on a cross-sectoral level, while support processes like ventilation, space heating and compressed air are cross-cutting, and also not as well monitored in general. It is also noted that production processes have several characteristics that make it difficult to analyze their EEU, such as being heterogeneous among firms, directly related to the core business of the 
firm, managed not by energy managers but by production managers, and confidential to outside auditors or researchers. All of these characteristics make production processes a more difficult target for energy audits in general, and for aggregated data presentation in particular. Support processes, on the other hand, usually are more homogeneous among firms, relatively separate from the core business, managed by energy managers, and less confidential, thus making energy audits for support processes easier.

The data after being collected were thoroughly examined and analyzed by the international research group, and even though large varieties in the data were found, an emphasis was to display the collected data in an as harmonized form as possible in this paper. For example, the data from Belgium were initially provided in PJ primary energy and converted to GWh in order to enable uniformity with Swedish and Italian data provided in GWh. Japanese data were not provided in energy units. When it comes to EEU, for example, the data were provided in the form of power consumption during peak hours by different end-use processes derived in \%. Energy savings for Japan were also defined in \% of the EEU. This was presented in the same way due to inability to define results in energy units.

\section{Results}

This section presents the datasets of EEU and EEMs obtained from the studied countries Belgium, Italy, Japan and Sweden. Enterprises have been categorized according to the ISIC International Standard Industrial Classification of all Economic Activities (ISIC) rev. 4 (United Nations Statistic division, 2012).

\subsection{Allocation of EEU and EEMs in Belgian industrial SMEs}

\section{EEU}

There were two datasets available on EEU and EEMs on two distinct segments of Belgian industry. The first set has been collected in the framework of a voluntary agreement (VA) schema, on energy efficiency in industry, targeting medium-sized industrial companies (an 
annual primary energy use 28-140 GWh/year (0.1-0.5 PJ/year) and started in 2005. More than 220 companies have taken part in the VA from various industrial sectors including chemicals and plastics, food and fodder, technology, textile, wood processing, printing and others (Cornelis, 2014). The purpose of the energy audits was to analyze the EEU and to detect EEMs with an internal rate of return of $15 \%$ at least. The participants to the VA then have the obligation to implement these measures. For further reading of the Belgian VA, please see Cornelis and Reunes (2012).

The second dataset has been collected during first-line energy audits carried out at SMEs (an annual primary energy use less than $28 \mathrm{GWh} / \mathrm{year}$, i.e. $0.1 \mathrm{PJ} / \mathrm{year}$ ) and hence beyond the scope of the abovementioned VA. In contrary to the energy audits of the VA, these first-line energy audits are purely informative and are meant to raise the awareness of the energysaving potential at the audited sites. First-line audits were carried out in 520 companies (195 companies can be regarded as industrial whereas the rest belong to the tertiary sector). The audits took place between 2008 and 2013 (Agentschap Ondernemen, 2014).

Table 1 and Figure 1 show the sectoral breakdown of EEU, reported for 2005 and covering 227 medium-sized companies that acceded the VA (Commissie Auditconvenant Vlaanderen, 2006, 2007 and 2008). Electricity use takes about 46.8\% of the total EEU and heat the remaining part.

Table 1. Number of medium-sized companies for two data sets, Flanders, Belgium according to sector.

\begin{tabular}{|l|c|c|}
\hline \multicolumn{1}{|c|}{ Sector } & $\begin{array}{c}\text { Number of companies, the } \\
\text { VA }\end{array}$ & $\begin{array}{c}\text { Number of companies, the } \\
\text { first-line energy audits }\end{array}$ \\
\hline C10 - Food \& beverages & 70 & 36 \\
\hline C13, C16- Textile \& wood & 33 & 30 \\
\hline $\begin{array}{l}\text { C20, C22 - Chemicals \& Plas- } \\
\text { tics }\end{array}$ & 57 & 23 \\
\hline C28 - Machinery (Technology) & 46 & 41 \\
\hline
\end{tabular}




\begin{tabular}{|l|c|c|}
\hline C18 - Printing industry & & 24 \\
\hline Others & 21 & 41 \\
\hline Total & $\mathbf{2 2 7}$ & $\mathbf{1 9 5}$ \\
\hline
\end{tabular}

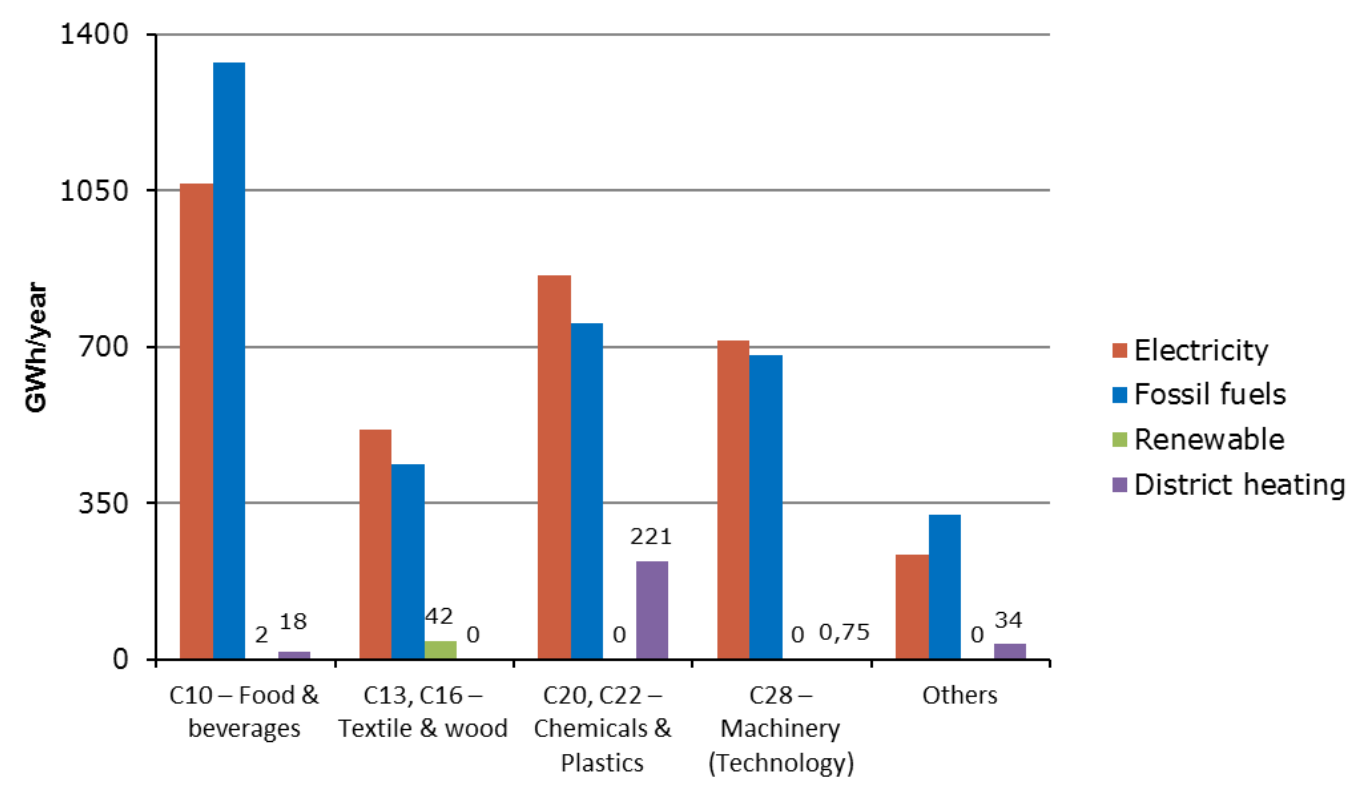

Figure 1. EEU of medium-sized companies $(\mathrm{N}=227)$ from the VA in Flanders, Belgium according to sector and energy carrier.

The energy audits that were carried out in the framework of the VA did not include a division of the EEU by process type in a harmonized way, if subdivided at all. Hence, EEU per process type cannot be given for the companies that participated in this VA.

Figures 2 and 3 show the average final fuel and electricity consumption from the first-line energy audits at the SMEs. Electricity takes about $41 \%$ of the total EEU and heat the remainder. On average $18 \%$ of the electricity use is for lighting, $8 \%$ for compressed air production and $15 \%$ for cooling. These figures do not vary considerably from one sector to another, apart from the food and machinery industry, which present a higher electricity consumption for cooling (36\%) and compressed air production, respectively. 


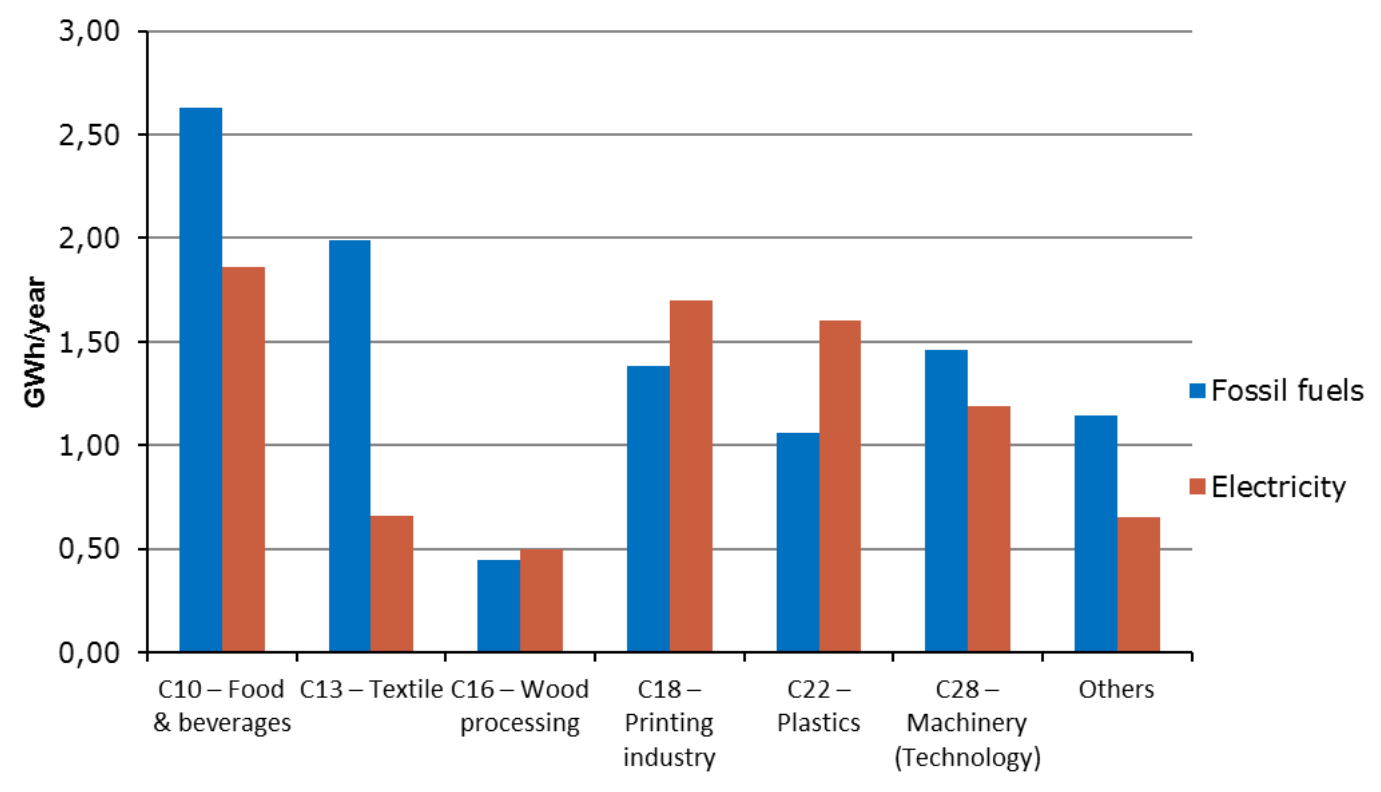

Figure 2. EEU of SMEs (N=195), the first-line energy audits, Flanders, Belgium according to sector and energy carrier.

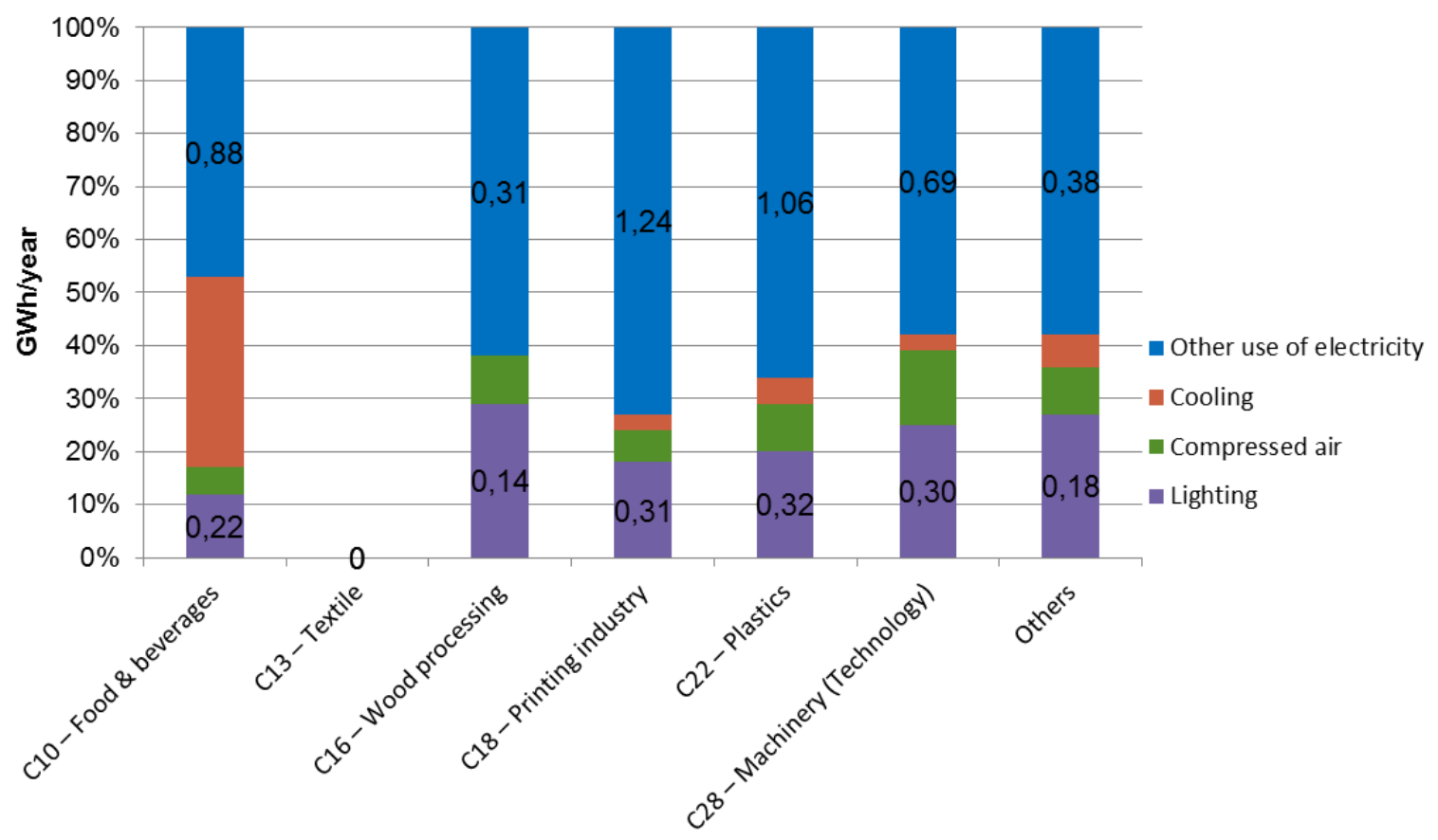

Figure 3: Share of EEU for different sectors in industrial SMEs $(\mathrm{N}=195)$, the first-line energy audits, GWh/year, Flanders, Belgium. 


\section{EEU efficiency potential}

The energy audits, carried out in 2006 at the medium-sized companies in the framework of the VA, resulted in about 2,300 energy-saving measures; they would, if implemented, save $880 \mathrm{GWh} /$ year of EEU or $12 \%$ of the total annual EEU.

One dimension in the categorization of data is whether the energy savings can be attributed to the core processes or to support processes, which further has been specified in building, lighting and cooling; the power system (for instance: the installation of a VSD, a high efficiency engine, etc.); air carriers (compressed air and vacuum) and heat carriers (steam, hot tap water and thermal oil). As Figure 4 illustrates, most energy savings can be realized in the core processes (46\%). In the support process, most energy savings can be realized in steam (23\%), cooling (8\%), power system (7\%) and compressed air (5\%). There are significant differences between the sectors; the process-related energy savings vary between $37 \%$ for sector $\mathrm{C} 13$, C16 - Textile \& wood and $66 \%$ for Others. However, when a second round of energy audits was carried out in the VA in the same companies in 2009 , the emphasis was put on energy savings related to the core process. About $60 \%$ of the energy savings detected in these energy audits were related to the core processes (Cornelis and Reunes, 2012). 


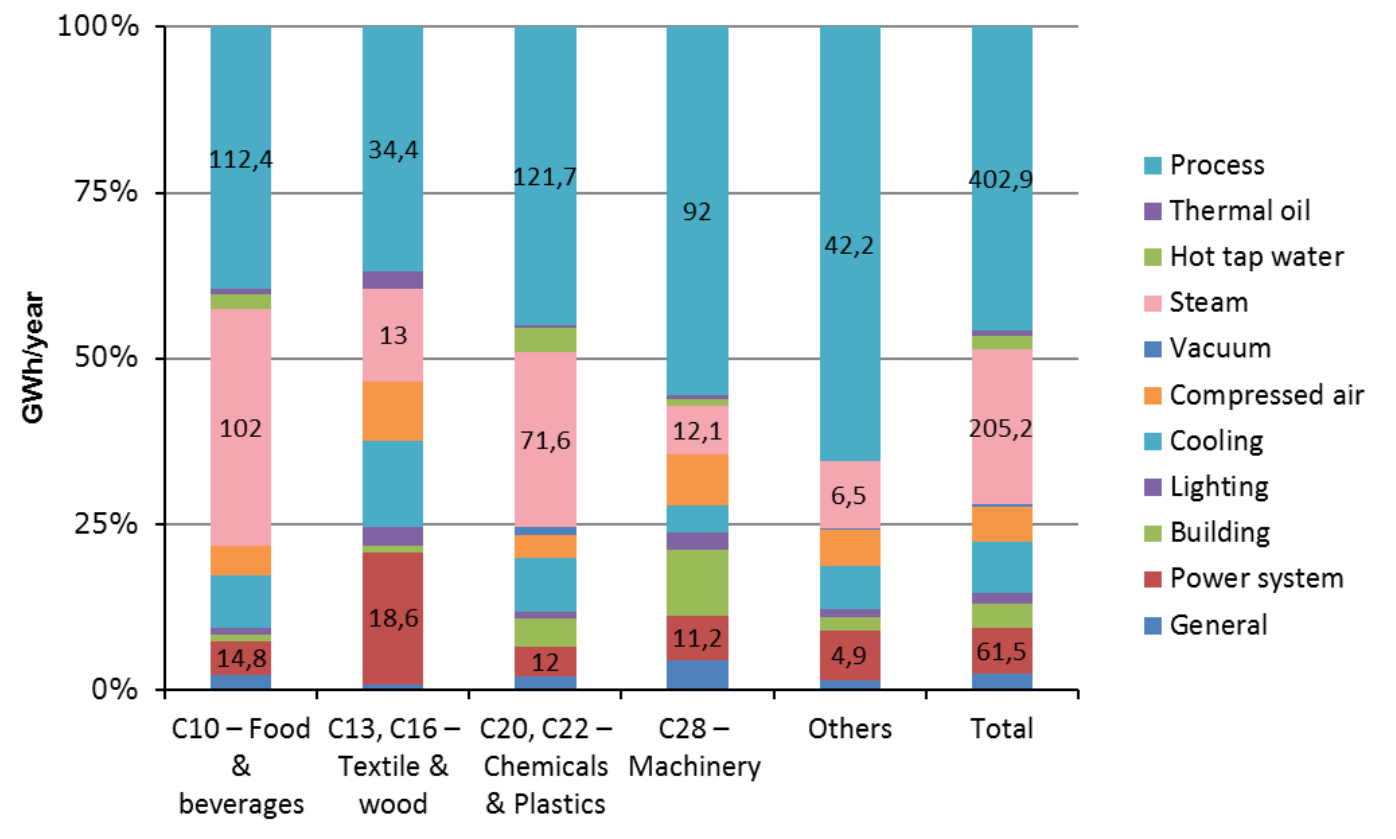

igure 4. Savings of proposed measures in energy audits for different processes and sectors, GWh/year $(\mathrm{N}=218)$, Belgium.

The number of measures is presented in Figure 5.

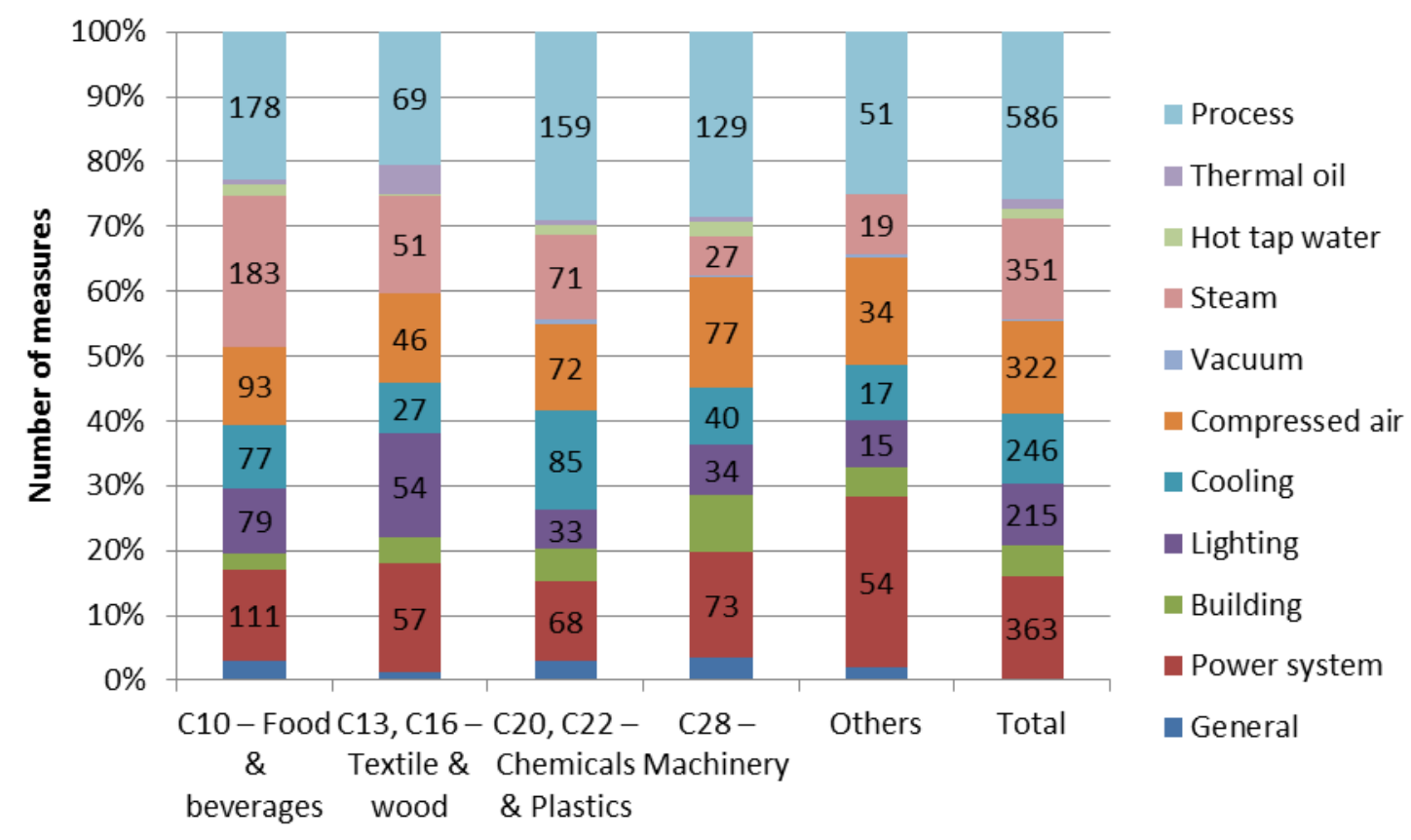

Figure 5: Number of measures per sector and per process type at medium-sized companies $(\mathrm{N}=218)$, Flanders, Belgium. 
Table 2 presents the average electricity and fuel savings that the first-line energy audits revealed for the SMEs. On average $7.4 \%$ on the electricity bill could be saved and $11.7 \%$ on the fuel bill. Agentschap Ondernemen [Enterprise Agency] (2014) only provides qualitative, not quantitative, indications on where energy could be saved. In the machinery industry, the major electricity savings were to be found in the compressed air system and the major fuel savings in the heating system for buildings. Upgrading the cooling system or recycling heat from it in the food industry can result in significant electricity savings in this sector. The most significant electricity savings in the other sectors can be found in lighting, compressed air and as a result of the installation of a VSD. The most significant measure to save fuel in other sectors was by replacing the boiler.

Table 2. Energy savings, \%, in industrial SMEs $(\mathrm{N}=195)$, the first-line energy audits for different sectors, Flanders, Belgium.

\begin{tabular}{|l|c|c|}
\hline \multicolumn{1}{|c|}{ Sector } & $\begin{array}{c}\text { Average electricity } \\
\text { savings, \% }\end{array}$ & $\begin{array}{c}\text { Average fuel } \\
\text { savings, \% }\end{array}$ \\
\hline C10 - Food \& beverages & 6.6 & 7.8 \\
\hline C13 - Textile & n/a & n/a \\
\hline C18 - Printing industry & 6.3 & 21.0 \\
\hline C16 - Wood processing & 12.7 & 9.2 \\
\hline C22 - Plastics & 6.8 & 18.7 \\
\hline C28 - Machinery (Technology) & 9.9 & 13.9 \\
\hline Others & 7.6 & $\mathbf{1 1 . 7}$ \\
\hline Total & $\mathbf{7 . 4}$ & \\
\hline
\end{tabular}




\subsection{Allocation of EEU and EEMs in Italian industrial SMEs}

\section{EEU}

Energy audit activities in a sample of 255 industrial SMEs (Table 3) has made it possible to draw a preliminary map of the EEU for production processes as well as major support processes (heating/ventilation/air conditioning [HVAC], compressed air and lighting). Table3 displays an overall view of the Italian dataset.

Table 3. Average number of employees and number of industrial SMEs for different sectors, Italy.

\begin{tabular}{|l|c|c|}
\hline \multicolumn{1}{|c|}{ Sector } & $\begin{array}{c}\text { Average number } \\
\text { of employees }\end{array}$ & $\begin{array}{c}\text { Number of } \\
\text { companies }\end{array}$ \\
\hline C10 - Food & 63 & 12 \\
\hline C13 - Textiles & 64 & 48 \\
\hline C16 - Wood & 35 & 19 \\
\hline C17 - Paper & 36 & 10 \\
\hline C22 - Plastic & 55 & 44 \\
\hline C23 - Non-metallic minerals & 49 & 5 \\
\hline C24 - Basic metals & 34 & 87 \\
\hline C25 - Primary metals & 43 & 7 \\
\hline C26 - Electronic and optical products & 79 & $\mathbf{2 5 5}$ \\
\hline Total & & 114 \\
\hline
\end{tabular}

The total annual EEU for all sectors was approximately $114 \mathrm{GWh}$ divided between the production processes and major support processes, and are presented in Figure 6. Production processes use $85 \%$ of energy (electricity and fuels). 


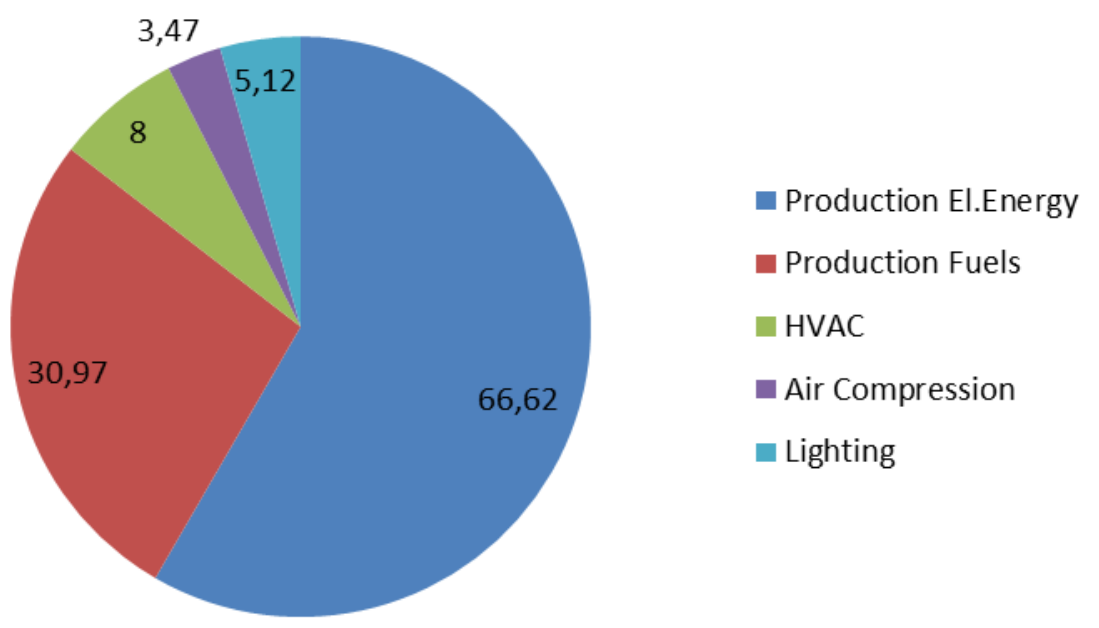

Figure 6. The total energy end-use per process type in industrial SMEs, GWh/year $(\mathrm{N}=255)$, Italy.

Figure 7 compares the EEU in the manufacturing activities involved in the research projects. Depending on the sector, electrical energy use by production processes ranges from $20 \%$ to $77 \%$.

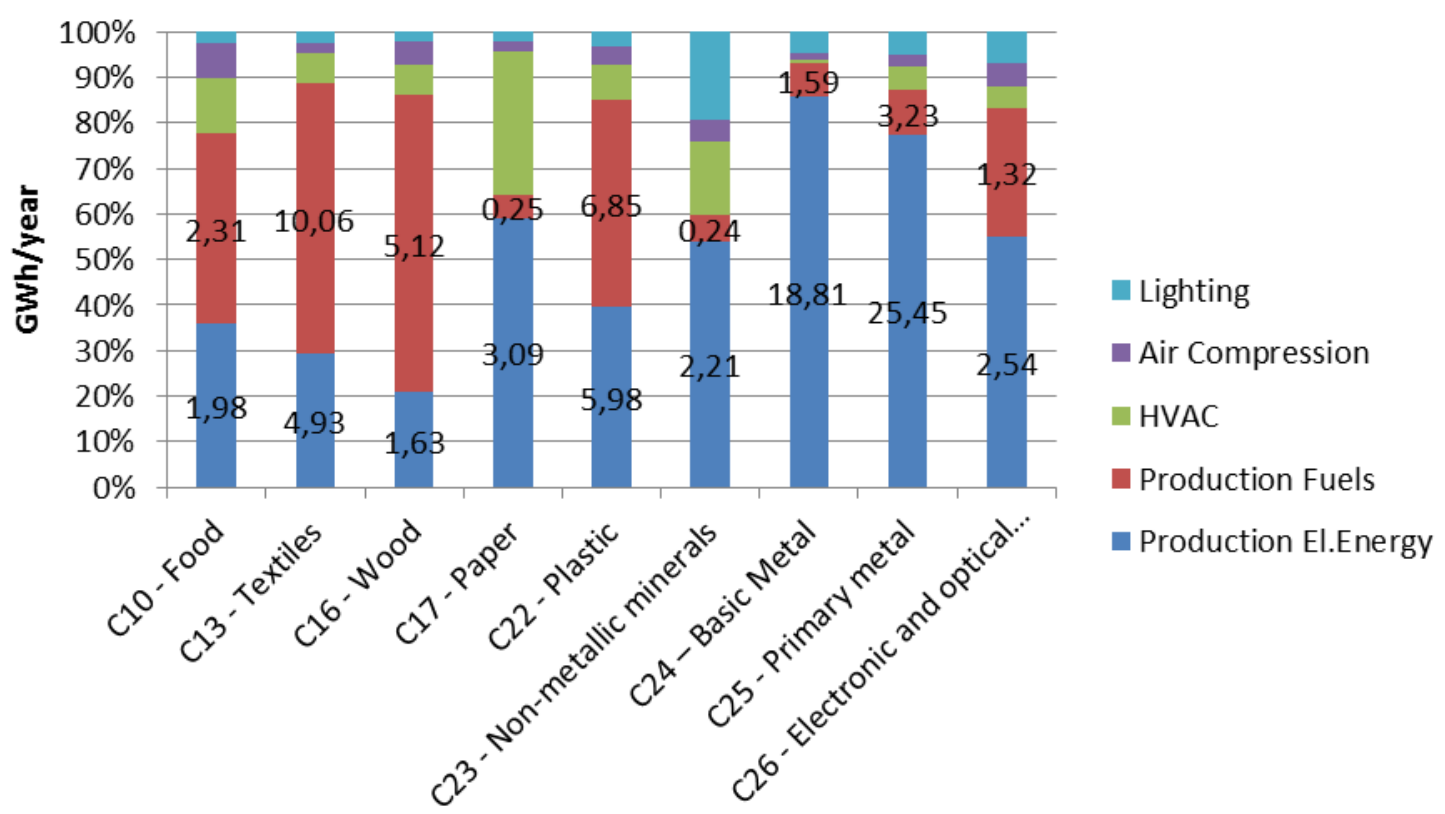

Figure 7. Share of EEU for different sectors in industrial SMEs, $G W h / y e a r(N=255)$, Italy.

Figure 7 highlights the major role of production processes, ranging from about $65 \%$ (pulp and paper manufacturing) to $90 \%$ (basic metal manufacturing). Moreover, here the role of 
major support processes is pointed out, e.g. for paper and non-metallic industries, as HVAC could represent a very relevant share of total usage (respectively, 32\% and 20\%). Compressed air covers a limited portion, never exceeding $10 \%$ of total usage. Nonetheless, limited to electric energy consumption, its role becomes much more relevant (17-18\% for food or wood manufacturing).

\section{EEU efficiency potential}

In Figure 8, a summary is presented of the total number of measures suggested by process area from the energy audits $(\mathrm{N}=255)$.

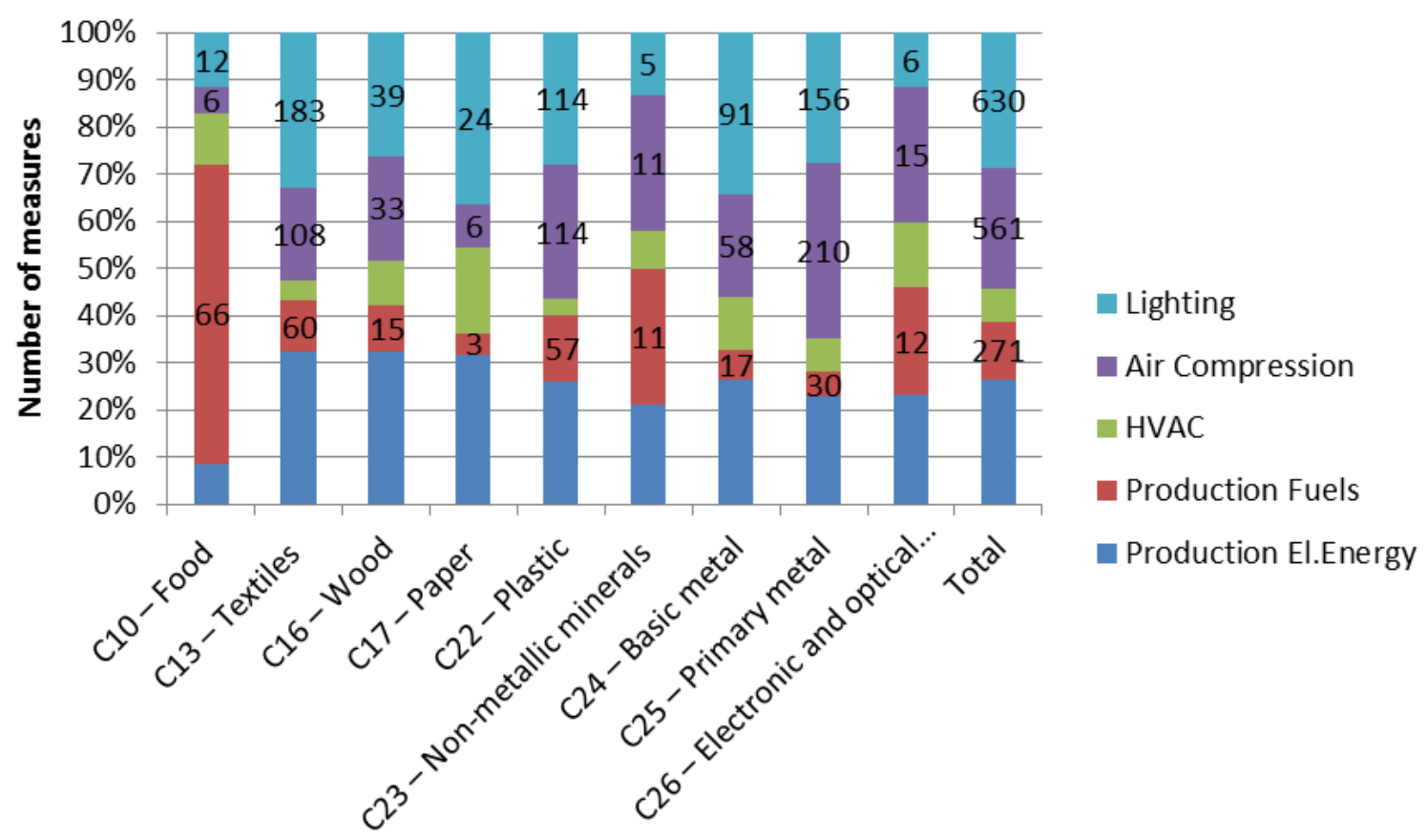

Figure 8 . The number of proposed measures in energy audits in industrial SMEs for different processes and sectors $(\mathrm{N}=255)$, Italy.

An average of nine EEMs per enterprise was proposed. The highest ratio was found within lighting systems (about two EEMs per enterprise), while one EEM in HVAC systems was suggested for about every two enterprises. Additionally, the number of suggested EEMs ranges from six per enterprise (primary metals manufacturing) up to 12 (basic metals manufacturing). When considering the distribution of EEMs by technology area, support systems 
(HVAC, air compression and lighting) cover about $60 \%$ of the proposed EEMs $(1,346$ out of 2,199 measures).

The calculations of energy savings (with respect to the EEU of each process type) have been conducted through a bottom-up approach considering single EEMs. In total the savings were found to be approximately $21 \mathrm{GWh} /$ year (18\% of the EEU). An average value of the achievable savings by process area is provided in Figure 9.

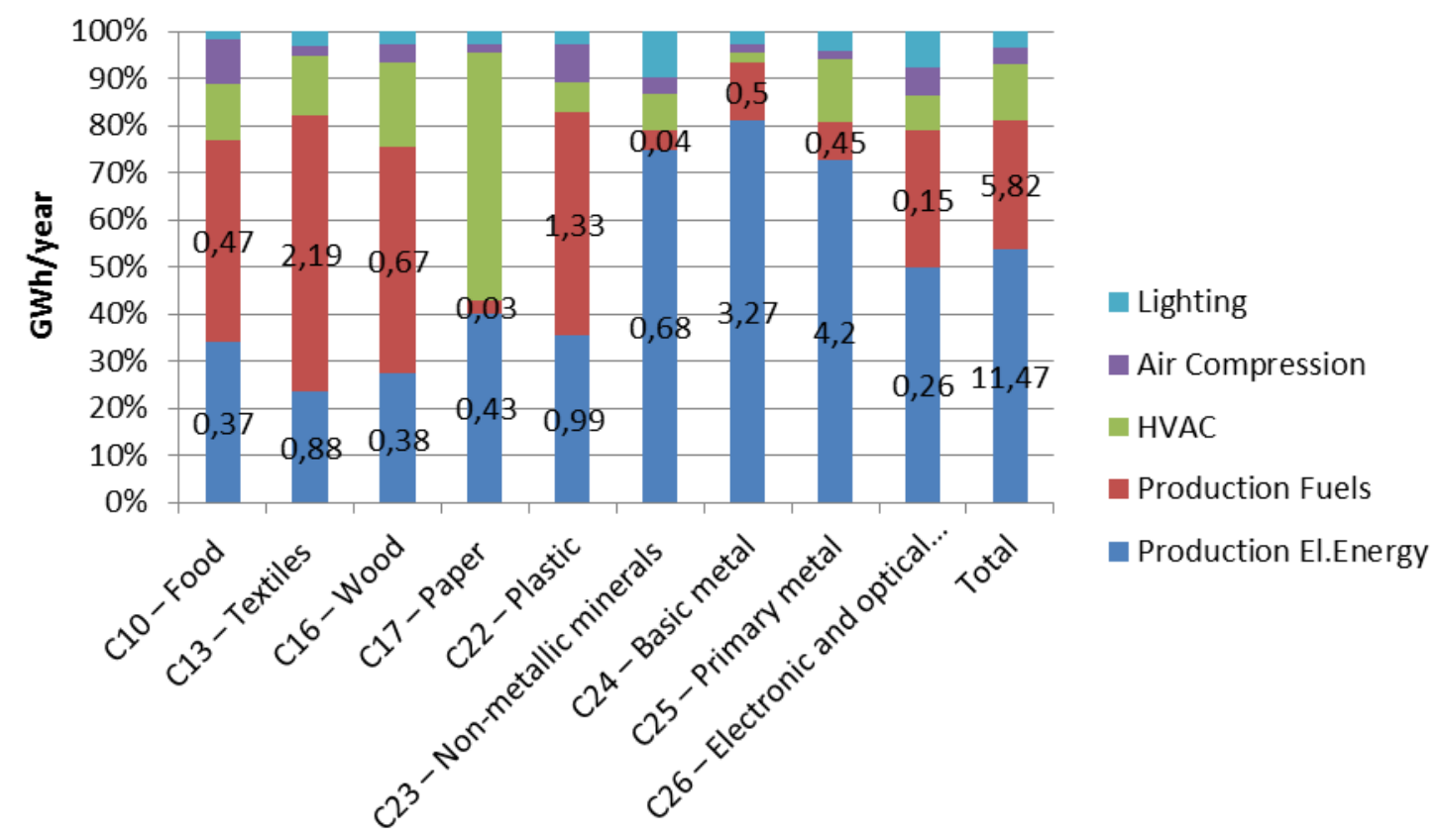

Figure 9. Energy savings of measures in energy audits in industrial SMEs for different processes and sectors, $\mathrm{GWh} /$ year $(\mathrm{N}=255)$, Italy.

In most cases, average savings by technology area are about $17-20 \%$. HVAC systems present higher values, where the savings can reach even more than $40 \%$, and an average of about $30 \%$. This is reasonable in case of very obsolete systems, as revealed by the performed energy audits.

\subsection{Allocation of EEU and EEMs in Swedish industrial SMEs}

\section{EEU}

In Sweden, data regarding EEU and EEMs were collected internally from the Swedish Energy Agency's energy audit program. The data underwent an extensive quality control by the 
national research group in charge of the data evaluation, where all data has been validated with the actual company-specific energy audit reports. For the EEU, the taxonomy used at the Swedish Energy Agency was the following:

- Space heating

- Tap hot water

- Ventilation

- Compressed air

- Lighting

- Space cooling

- Administration

- Other

- Production processes

The available data was only collected in the unit energy, i.e., it was not categorized based on energy carriers, e.g. electricity, oil, wood pellets. Only manufacturing industrial companies that had received funding for their energy auditing during 2011 and 2012 were included.

As regards data on EEU, 74 industrial SME companies were found useful. These companies used in total $437 \mathrm{GWh} /$ year, see Figure 10. A larger number of companies were collected (94), but could not be used due to lack of data regarding the EEU, i.e., this data was found to be lacking in the energy audit reports during the quality control.

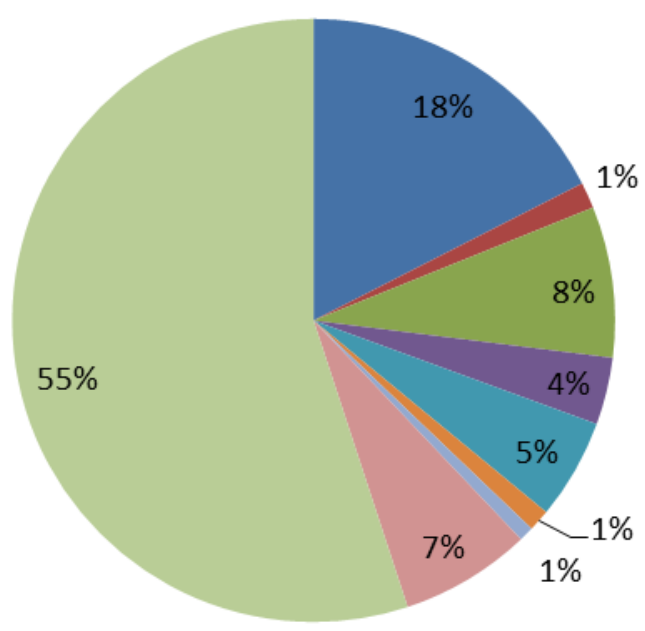

- Space heating

- Tap hot water

ventilation

- Compressed air

- Lighting

- Space cooling

Administration

- Other

Production processes 
Figure 10. Energy end-use per process type in industrial SMEs $(\mathrm{N}=74)$, Sweden.

As can be seen in Figure 10 the use in production processes accounts for $55 \%$ of the total EEU. The second largest user was space heating (18\%) followed by ventilation ( $8 \%)$. A more explicit presentation of the EEU from the different sectors is found in Figure 11.

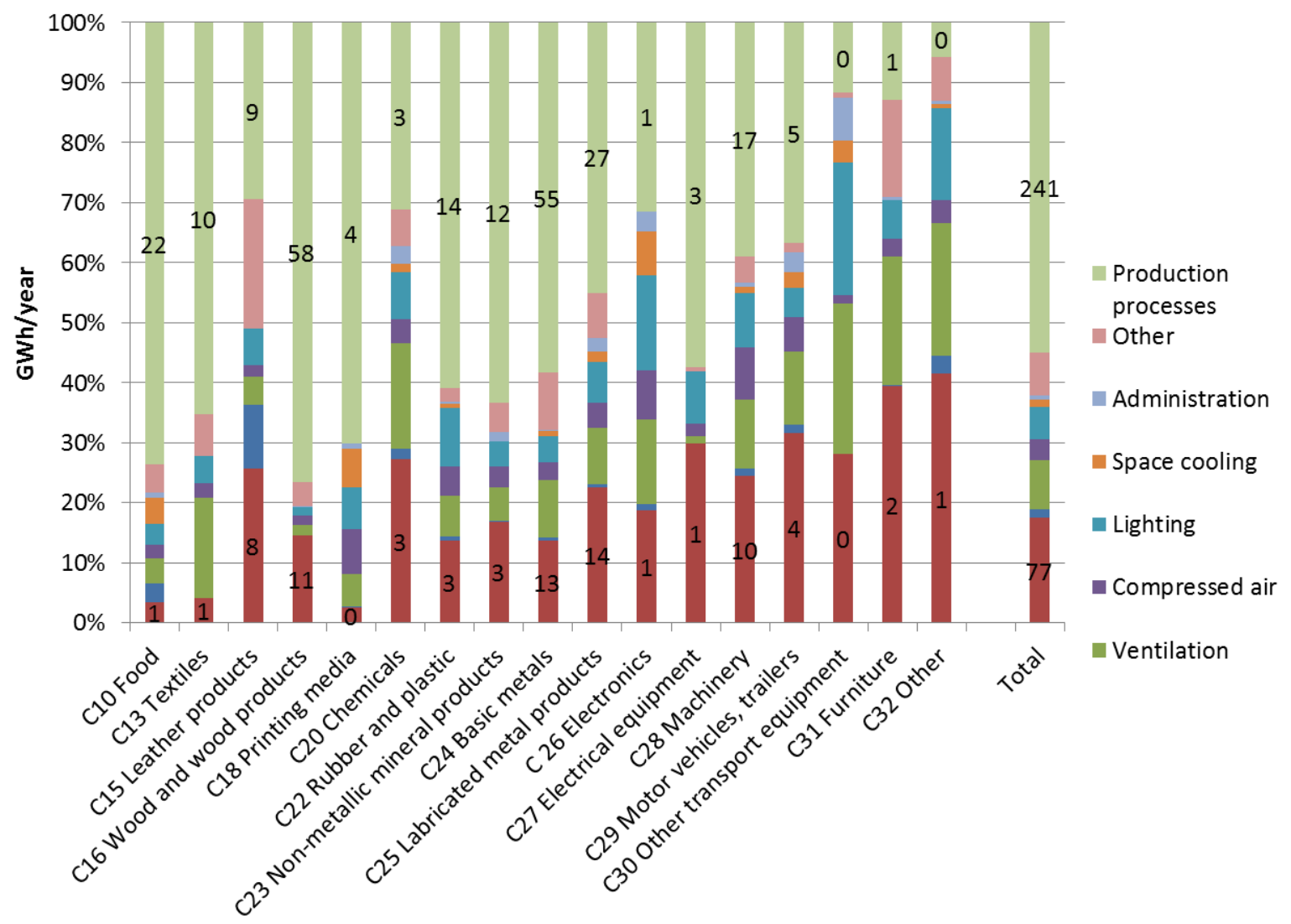

Figure 11. Share of EEU for different sectors in industrial SMEs $(N=74)$, Sweden.

Figure 11 shows that for nine of the 18 sectors, the majority of the EEU was found among the production processes. Results from Figures 10 and 11 thus reveal that among the collected set of data from industrial SMEs, about half of the EEU is found in the production processes, and half in the support processes. 


\section{EEU efficiency potential}

The energy efficiency potentials in the industrial SMEs from 74 industrial SMEs are presented in Figure 12. It is important to be careful when making conclusions from Figure 12 as some sectors only include one or a few companies.

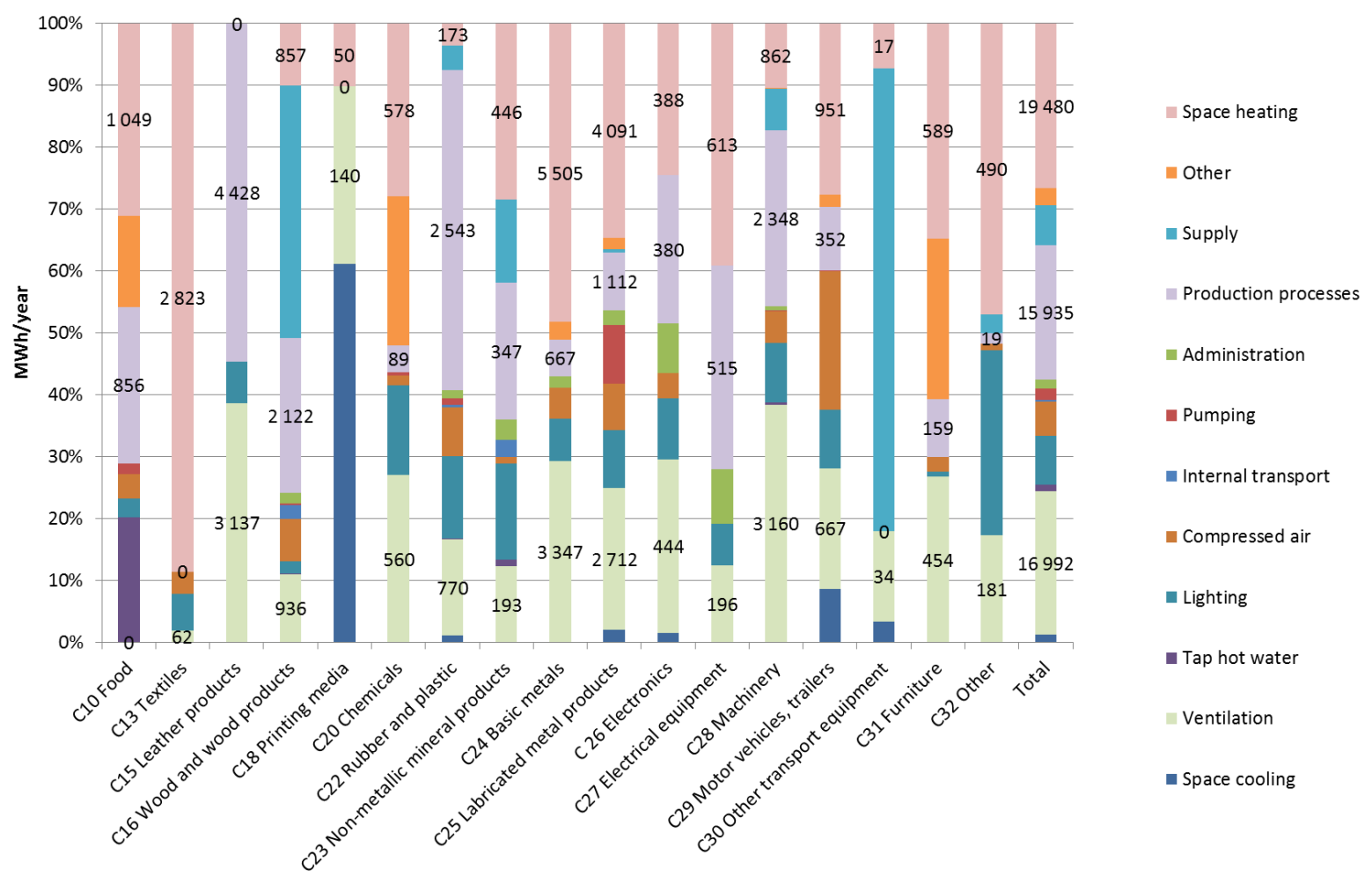

Figure 12. Energy-saving potential for different processes in the selected sectors $(\mathrm{N}=74)$, Sweden.

As can be seen in Figure 12, the energy-saving potential varies greatly between the different sectors. Table 4 shows in which processes the energy efficiency measures are found, e.g. production processes, ventilation, lighting, pumping, compressed air, etc. 
Table 4. Energy-saving potential and number of EEMs for different processes $(\mathrm{N}=74)$, Sweden.

\begin{tabular}{|c|c|c|c|}
\hline Processes & \# of measures & Savings, GWh/yr & Savings, $\%$ \\
\hline Space heating & 147 & 19.5 & $27 \%$ \\
\hline Space cooling & 11 & 0.94 & $1 \%$ \\
\hline Ventilation & 139 & 17.0 & $23 \%$ \\
\hline Tap hot water & 8 & 0.75 & $1 \%$ \\
\hline Lighting & 114 & 5.8 & $8 \%$ \\
\hline Compressed air & 59 & 4.0 & $6 \%$ \\
\hline Internal transport & 5 & 0.26 & $0 \%$ \\
\hline Pumping & 14 & 1.3 & $2 \%$ \\
\hline Administration & 14 & 1.1 & $1 \%$ \\
\hline Production processes & 76 & 15.9 & $22 \%$ \\
\hline Supply & 14 & 4.7 & $6 \%$ \\
\hline Other & 12 & 2.1 & $3 \%$ \\
\hline Total & 613 & 73.3 & $100 \%$ \\
\hline
\end{tabular}

The total savings account for approximately 17\% of industrial EEU (73.3 GWh). The highest number of measures was found in Space heating followed by Ventilation and Lighting. The largest total savings were found in Space heating followed by Ventilation and Production processes. It should be noted that despite the fact that the majority of the EEU on average are found in the production processes, the majority of the energy efficiency measures were not found in the production process, but among the support processes.

\subsection{Allocation of EEU and EEMs in Japanese industrial SMEs}

\section{EEU}

In Japan data on the allocation of EEU in industrial SMEs are very scarce. There is no database available or large surveys. Even case reports seems very limited, party because submetering of EEU is not common in industrial SMEs in Japan. Understanding EEU in industri- 
al SMEs is also difficult because of the diversity of equipment and its usage in those firms. However, there are several literature reports that provide data on the allocation of EEU in industrial SMEs. Since these are case studies or small surveys based on a limited number of samples, they do not provide representative figures. Nevertheless, they may be considered useful for understanding "typical” EEU in industrial SMEs in Japan.

Figure 13 presents one such example, comparing typical EEU of electricity during peak hours of SMEs in different industries (METI, 2011). One can observe that in industrial SMEs, production processes have the largest share, using approximately half of the electricity use, followed by air conditioning and motor-driven systems (compressors, pumps and fans).

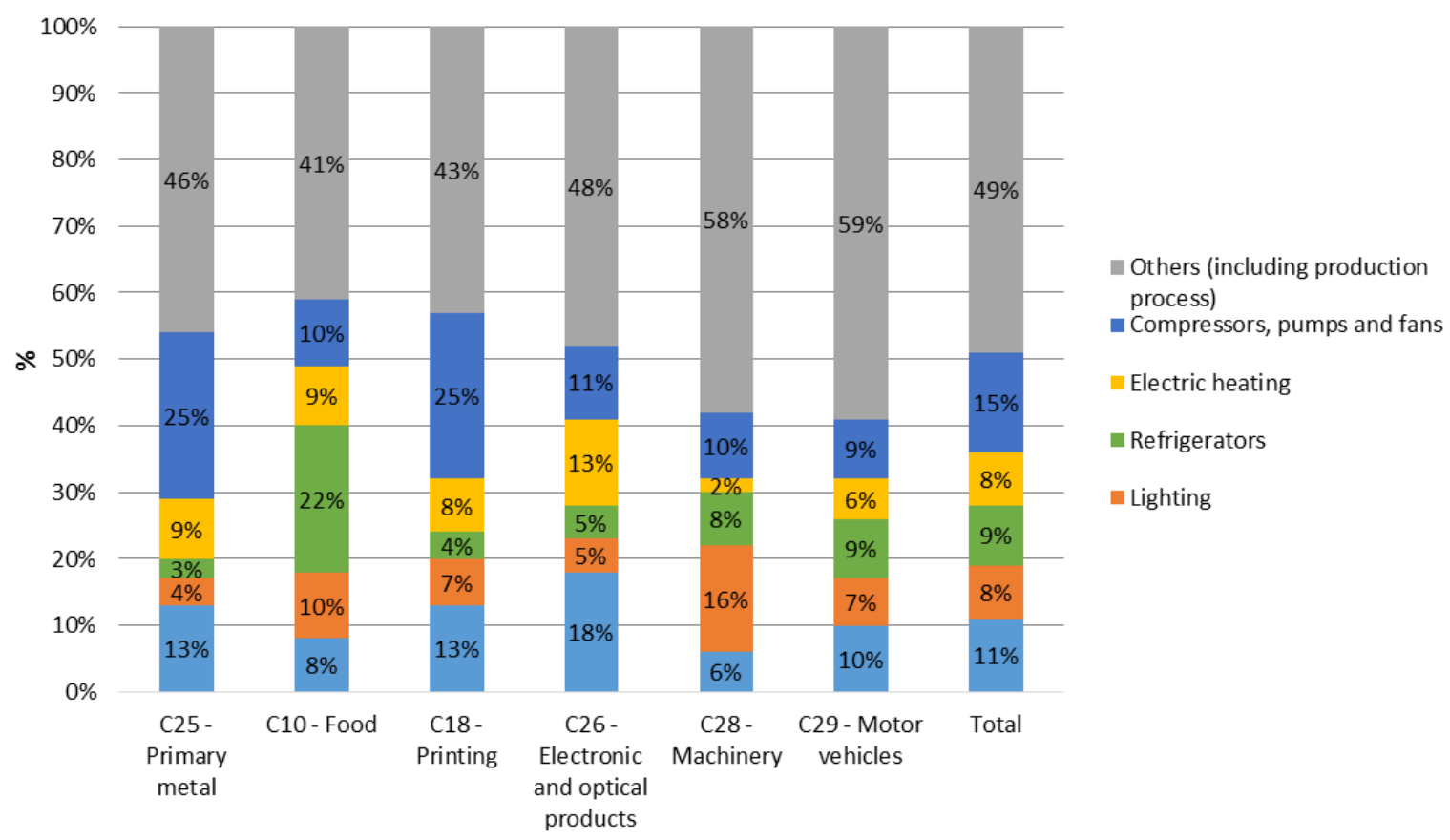

Figure 13. Share of electricity demand among processes in typical industrial SMEs, Japan.

\section{EEU efficiency potential}

Energy-saving potential in industrial SMEs was surveyed in an energy audit program for industrial SMEs conducted by Energy Conservation Center Japan (ECCJ), and is presented in Figure 14 (ECCJ, 2011). 


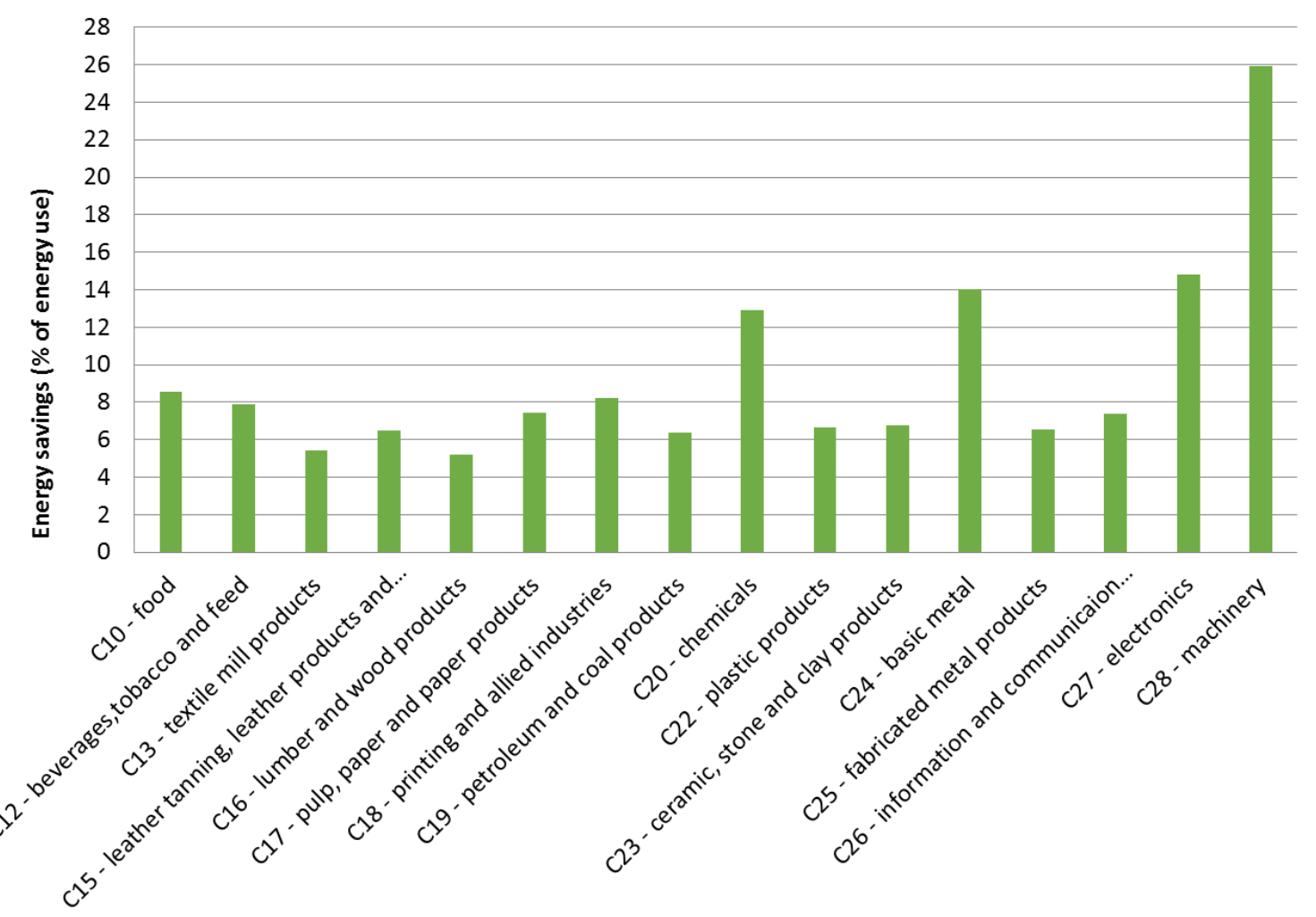

Figure 14. Energy-saving potential in selected industries, Japan.

Figure 14 shows that energy-saving potential in SMEs (including non-manufacturing industries) ranges from $5 \%$ to $26 \%$. The data are obtained from energy audits conducted by ECCJ (ECCJ, 2011) from 1997 to 2010 (number of companies is 2,680). Note that potential savings represent estimated savings that could be realized by implementing measures proposed in the audits.

While data on energy-saving potential by measures or by EEU are not available from ECCJ, the number of measures proposed in the audits conducted by ECCJ in 2008 (ECCJ, 2011 ) is available and presented in Table 5 (number of companies is 3,139). 
Table 5. The number and types of proposed measures in industrial SMEs for different processes $(\mathrm{N}=3,139)$, Japan.

\begin{tabular}{|c|c|c|}
\hline Category & Measure & $\begin{array}{c}\text { \# of proposed } \\
\text { measures }\end{array}$ \\
\hline \multirow{3}{*}{$\mathrm{A} / \mathrm{C}$ and refrigerators } & management of air-conditioning system & 345 \\
\hline & temperature setting of air-conditioners & 144 \\
\hline & management of freezers and refrigerators & 36 \\
\hline \multirow{5}{*}{ Fans, pumps and compressors } & management of air pressure & 268 \\
\hline & introducing variable-speed drives & 246 \\
\hline & operation improvement & 220 \\
\hline & avoiding leakage of air & 110 \\
\hline & reduction of demand & 46 \\
\hline \multirow{7}{*}{ Boilers and furnaces } & insulation & 260 \\
\hline & combustion management & 178 \\
\hline & operation improvement & 125 \\
\hline & waste heat recovery & 41 \\
\hline & reduction of steam pressure & 41 \\
\hline & avoiding leakage of steam & 40 \\
\hline & steam drain recovery & 33 \\
\hline \multirow{6}{*}{$\begin{array}{l}\text { Lighting and other electric } \\
\text { equipment }\end{array}$} & management of power receiving equipment & 248 \\
\hline & introducing high-efficiency lightings & 218 \\
\hline & operation improvement of lightings & 196 \\
\hline & management of power conversion equipment & 128 \\
\hline & improving motor efficiency & 90 \\
\hline & operation improvement of electric equipment & 73 \\
\hline
\end{tabular}

Another detailed data set of the energy-saving potential in industrial SMEs was available from a small survey conducted by a consultant company based on a commission by METI (Land Brains, 2009), see Table 6. It conducted energy audits in 15 SMEs, eight of which were manufacturing firms. 
Table 6. Energy-saving potential (\% of annual energy end-use) in eight manufacturing SMEs, Japan.

\begin{tabular}{|c|c|c|c|c|c|c|c|}
\hline & $\begin{array}{l}\text { Replacing } \\
\text { air- } \\
\text { condition- } \\
\text { ers }\end{array}$ & $\begin{array}{l}\text { Intermit- } \\
\text { tent con- } \\
\text { trol of air- } \\
\text { condition- } \\
\text { ers }\end{array}$ & $\begin{array}{l}\text { Introduc- } \\
\text { ing high- } \\
\text { efficiency } \\
\text { lighting }\end{array}$ & $\begin{array}{c}\text { Changing } \\
\text { tempera- } \\
\text { ture set- } \\
\text { ting of } \\
\text { space } \\
\text { heating \& } \\
\text { cooling }\end{array}$ & $\begin{array}{l}\text { Reduc- } \\
\text { ing air } \\
\text { pres- } \\
\text { sure }\end{array}$ & $\begin{array}{c}\text { Reducing } \\
\text { tempera- } \\
\text { ture of } \\
\text { intake-air } \\
\text { of compres- } \\
\text { sors }\end{array}$ & Total \\
\hline $\begin{array}{l}\text { C11 - Beverages } \\
\text { (Brewery) }\end{array}$ & $5.1 \%$ & & & $0.20 \%$ & & $0.20 \%$ & $5.5 \%$ \\
\hline C18 - Printing & & $2.7 \%$ & & $7.9 \%$ & & & $10.6 \%$ \\
\hline $\begin{array}{l}\text { C20-Chemicals } \\
\text { (Thin-film for } \\
\text { lamps) }\end{array}$ & & $2.6 \%$ & $2.8 \%$ & & $2.2 \%$ & $0.70 \%$ & $8.3 \%$ \\
\hline $\begin{array}{l}\text { C22 - Plastics } \\
\text { (Polyethylene } \\
\text { film) }\end{array}$ & $9.4 \%$ & & $4.4 \%$ & & & & $13.8 \%$ \\
\hline $\begin{array}{l}\text { C25 - Basic metal } \\
\text { (Duct) }\end{array}$ & & $0.90 \%$ & $4.4 \%$ & $3.8 \%$ & $0.80 \%$ & & $9.9 \%$ \\
\hline $\begin{array}{l}\text { C25 - Basic metal } \\
\text { (Pipes) }\end{array}$ & & & $6.9 \%$ & & & & $6.9 \%$ \\
\hline $\begin{array}{l}\text { C } 26 \text { - Electronic } \\
\text { and optical prod- } \\
\text { ucts }\end{array}$ & & & $5.7 \%$ & & $1.4 \%$ & & $7.1 \%$ \\
\hline $\begin{array}{l}\text { C27 - Electrical } \\
\text { equipment (Elec- } \\
\text { tric cable) }\end{array}$ & & & $2.3 \%$ & & $0.90 \%$ & $0.30 \%$ & $3.5 \%$ \\
\hline
\end{tabular}

\section{Analysis}

\subsection{Summary of categorizing EEU and EEMs among industrial SMEs in}

\section{Belgium, Italy, Japan, Sweden}

The categorization of data obtained in respective countries is summarized and presented in

Table 7.

Table 7. The categorization of data obtained in respective countries.

\begin{tabular}{|c|c|c|c|c|c|}
\hline & Belgium & & & \\
Parameter analyzed & $(227$ & Belgium & Italy & Japan & Sweden \\
& medi- & $(195$ & $(255$ & (several & (74 SMEs) \\
& um- & SMEs) & SMEs) & samples) & \\
\hline
\end{tabular}




\begin{tabular}{|l|c|c|c|c|c|}
\hline EEU per process type & $\begin{array}{c}\text { N/A (only } \\
\text { total EEU } \\
\text { per sec- } \\
\text { tor) }\end{array}$ & GWhn/a & GWh & $\begin{array}{c}\text { N/An/a } \\
\text { (only total } \\
\text { EEU per } \\
\text { sector) }\end{array}$ & GWh \\
\hline $\begin{array}{l}\text { EEU per different processes } \\
\text { per different sectors }\end{array}$ & N/A & GWh & GWh & $\begin{array}{c}\text { n/a\% (ex- } \\
\text { pert judg- } \\
\text { ment on } \\
\text { electricity } \\
\text { demand) }\end{array}$ & GWh \\
\hline $\begin{array}{l}\text { EEM per different process- } \\
\text { es per different sectors }\end{array}$ & $\#$ measures & N/A & \# measures & $\begin{array}{c}\text { \# measures } \\
\text { (only per } \\
\text { processes) }\end{array}$ & measuresn/a \\
\hline $\begin{array}{l}\text { Energy -saving potential } \\
\text { per different processes per } \\
\text { different sectors }\end{array}$ & GWh & $\begin{array}{c}\% \text { (only } \\
\text { per sector) }\end{array}$ & GWh & $\begin{array}{c}\% \text { (only per } \\
\text { processes) }\end{array}$ & GWh \\
\hline
\end{tabular}

In the first column, different categories of data obtained from the participating countries are presented. As stated before, EEU data from Belgium was not prevalent for the VA. Italy and Sweden presented the data for the same sample size for both EEU and EEMs (255 SMEs in Italy and 74 SMEs in Sweden). However, for Japan, there were several different sample sizes used: a survey by Tokyo Metropolitan Government SMEs (153 SMEs), another survey by Tokyo Metropolitan Government SMEs (16 SMEs from food sector), an energy audit program (3,731 SMEs, etc.) (Tokyo Metropolitan Government, 2007, 2008a, 2008b, 2012). This made it extremely difficult to structure the data in a harmonized way.

\subsection{Allocation of EEU in industrial SMEs}

In the following section, the data with regards to the country-specific presentations of EEU are further analyzed and discussed. For many sectors in the presented country-specific data sets, only one country had figures, for which reason these sectors were left out in the analysis section, as no general findings may be found in relation to these sectors. It is worth repeating that Japanese data is presented by the power consumption by different processes in different industries which can be assumed to reflect the EEU by corresponding processes in these industries. 
When it comes to SMEs in the food, textile and forestry industries in the studied countries, it was apparent from the data from Italy and Sweden that the majority of the EEU was found in the production processes, while for Japan, the production accounted for roughly $40 \%$ of electricity consumption, while figures for the textile and forestry industry were lacking. In the printing industry in Sweden, the majority of the EEU was found in the production processes, while for Japan, again only electricity consumption was available, which showed that production accounted for roughly $40 \%$ of the EEU. In the non-metallic mineral products sector, the Italian and Swedish data set showed that the majority of the EEU was found in the production processes. The same holds for basic metals in Italy, while for Sweden, about half of the energy use was found in the production processes for the basic metal sector. As regards SMEs in primary metals, about half of the EEU was found in the production processes in Sweden, while for Italy, the production processes accounted for about $85 \%$ of the EEU. Japan, providing only electricity consumption data for primary metals, had roughly $45 \%$ of power consumption allocated to the production processes.

About $30 \%$ of the EEU was found in the production processes in the electronics industry in Sweden, while for Italy, the production processes accounted for about $85 \%$ of the EEU in this sector. In Japan, the production represented half of the electricity consumption. SMEs in the machinery and motor vehicles industries use about $65 \%$ of energy in the support processes, while for Japan, roughly $60 \%$ of electricity is consumed by the production processes. In total, about $85 \%$ of the EEU in Italy was found to be in the production processes, while for Sweden about $50 \%$ of the industrial EEU was found in the production processes. For Japan too, about $50 \%$ of the electricity was consumed in the production processes. Figures for Belgium were lacking. These findings call for further future research, trying to find underlying mechanisms for these large differences both between processes in the overall data set, as well as well 
among specific sectors. Most likely, such research demands a common classification scheme prior to conducting the audits. These findings are summarized in Table 8 .

Table 8. The allocation of EEU in industrial SMEs in respective countries.

\begin{tabular}{|c|c|c|c|c|}
\hline Sector & EEU, Belgium & EEU, Italy & EEU, Sweden & $\begin{array}{l}\text { Electricity con- } \\
\text { sumption, Ja- } \\
\text { pan }\end{array}$ \\
\hline $\begin{array}{l}\mathrm{C} 10, \mathrm{C} 13, \mathrm{C} 16- \\
\text { food, textile and } \\
\text { wood }\end{array}$ & \multirow{8}{*}{$\begin{array}{l}\text { No data for pro- } \\
\text { duction process- } \\
\text { es }\end{array}$} & \multicolumn{2}{|c|}{ Major part, production processes } & $\begin{array}{l}40 \% \text {, production } \\
\text { processes, food } \\
\text { sector }\end{array}$ \\
\hline $\begin{array}{l}\text { C18 - printing } \\
\text { industry }\end{array}$ & & $\mathrm{n} / \mathrm{a}$ & $\begin{array}{l}\text { Major part, pro- } \\
\text { duction process- } \\
\text { es }\end{array}$ & $\begin{array}{l}40 \% \text {, production } \\
\text { processes }\end{array}$ \\
\hline $\begin{array}{l}\mathrm{C} 23-\text { non- } \\
\text { metallic mineral } \\
\text { products }\end{array}$ & & \multicolumn{2}{|c|}{ Major part, production processes } & $\mathrm{n} / \mathrm{a}$ \\
\hline $\begin{array}{l}\mathrm{C} 24-\text { basic } \\
\text { metals }\end{array}$ & & \multicolumn{2}{|c|}{ Major part, production processes } & $\mathrm{n} / \mathrm{a}$ \\
\hline $\begin{array}{l}\mathrm{C} 25-\text { primary } \\
\text { metals }\end{array}$ & & $\begin{array}{l}85 \% \text {, production } \\
\text { processes }\end{array}$ & $\begin{array}{l}45 \%, \text { production } \\
\text { processes }\end{array}$ & $\begin{array}{l}45 \% \text {, production } \\
\text { processes }\end{array}$ \\
\hline $\begin{array}{l}\text { C27 - electron- } \\
\text { ics }\end{array}$ & & $\begin{array}{l}85 \% \text {, production } \\
\text { processes }\end{array}$ & $\begin{array}{l}\text { Major part, pro- } \\
\text { duction process- } \\
\text { es }\end{array}$ & $\begin{array}{l}50 \% \text {, production } \\
\text { processes }\end{array}$ \\
\hline $\begin{array}{l}\text { C28 - machin- } \\
\text { ery and motor } \\
\text { vehicles }\end{array}$ & & $\mathrm{n} / \mathrm{a}$ & $\begin{array}{l}60 \%, \quad \text { support } \\
\text { processes }\end{array}$ & $\begin{array}{l}60 \% \text {, production } \\
\text { processes }\end{array}$ \\
\hline Summary & & $\begin{array}{l}85 \% \text {, production } \\
\text { processes }\end{array}$ & $\begin{array}{l}85 \%, \text { production } \\
\text { processes }\end{array}$ & $\begin{array}{l}50 \% \text {, production } \\
\text { processes }\end{array}$ \\
\hline
\end{tabular}

For Italy and Sweden, the EEU allocation was shown to differ greatly between the data sets. One general finding was that the production EEU was found to be larger in the Italian data set than in the Swedish. The major reason for this is that Sweden has a tradition of using electricity for many processes while for other European countries, other forms of energy are chosen. This was exemplified in a comparison of choice of energy carrier in the foundry industry (Thollander et al., 2005). As EEU is studied, primary energy is not displayed, and thus 
results in higher figures for companies who are using e.g. oil with major losses in the boiler, etc.

\subsection{Where is the energy efficiency potential found in industrial SMEs?}

For industrial SMEs, the potential for improved energy efficiency in the production processes was found to be about $20 \%$ for both Italy and Sweden. For Belgium, the second largest EEM in the VA (after the measures in the production processes) was found in the steam system, followed by cooling and power systems; the data regarding processes were not available for the first-line energy audits. For Italy the largest figure apart from production processrelated EEMs was found in the HVAC systems, followed by compressed air and lighting. For Sweden, the largest energy efficiency potential was found in space heating followed by ventilation and production process-related EEMs were only in third place. The high figure for Belgium is related to the fact that the Belgian data set consists of medium-sized energy-intensive companies taking part of the Belgian VA, while the datasets for Sweden and Italy are related to a less homogeneous set of industrial SMEs. As for Japan, the data was only based on eight companies, and did not use production processes or steam in the categorization of measures, for which reason no general figure could be presented, based on that dataset.

In summary, the non-homogeneous data did not allow for a deeper analysis and comparison between countries, processes or sectors. Here, a great relevance of promoting a common structure for gathering bottom-up information about EEU as well as energy efficiency potential is shown. This is discussed further in the following section of the paper.

\subsection{The need of a new taxonomy for categorizing EEU and EEMs among industrial SMEs}

The categorization of data from the respective country revealed a vast amount of various ways of categorizing EEU data and EEMs. Even though all four countries have a large indus- 
trial sector, the review found no standardized way of categorization. Also, the scientific literature background showed a number of different ways of categorizing data.

A general EEU taxonomy would greatly enhance the knowledge of bottom-up data, and is suggested to include a division between "Production processes" and "Support processes" for industrial SMEs. Support processes may also be called "auxiliary processes," "non-production processes" and so on. However, to be clear that the processes referred to are actually supporting production, the term "Support processes" is suggested. Moreover, it is suggested that such taxonomy should include an array of processes under the category Support processes, e.g.: Compressed air, Lighting, Ventilation, Space heating, Space cooling, Internal transport, Pumping, Administration, Tap hot water, and maybe also Steam and Vacuum system. However, the array of processes under Support processes has to be explored more in detail before being decided upon. For example, pumping is in some industries difficult to exclude from production processes as well as compressed air. According to the findings reported from the data comparison, it seems that the more non-energy intensive and the smaller the company, the easier it is to make a clear distinction between production processes and support processes. When moving towards more energy-intensive industries and medium-sized industries, it seems from the results that the distinction is not as clear.

Also, the category "Production processes" could be divided into sub-categories, like in the unit process concept (Thollander et al., 2012). However, Production processes could be most useful without sub-categories, because the production systems of industrial SMEs are greatly diversified. According to the results it seems that the less energy intensive and the smaller the company is, the less importance EEU has in the production processes. When moving towards developing a general taxonomy for more energy-intensive industries and medium-sized industries, results suggest that the share of EEU for Production processes increases. For energyintensive companies, such general taxonomy would be less useful as the majority of EEU is 
found in the production system and these differ greatly between sectors. Thus, it is suggested that sector-specific production processes are structured under this category, thus enabling a general taxonomy not only for industrial SMEs but also for energy-intensive and larger industrial companies.

As for categorization of EEMs, research has been conducted by e.g. Trianni et al. (2014) and Fleiter et al. (2012), but in regard to EEU, less work has been done. For the sake of simplicity and for follow-up reasons, it is recommended that the taxonomy for EEU be integrated with the research already presented concerning EEMs, with at least an integration of type of sector, and type of process (support and production processes, etc. While the integration in regard to type of modification is important to use, it is more difficult to integrate with EEU data.

\section{Concluding discussion}

The Belgian and Swedish datasets were collected from national energy agencies, stemming from governmental industrial energy policy programs, while for Italy, the data were collected from research-oriented industrial energy audits. For Japan, the data were collected from trade organizations, as no national data from e.g. energy audit programs was available. While the data from Italy distinguished between energy-intensive and non-energy-intensive companies, the Swedish and Japanese data did not make such distinctions. For Belgium, two datasets were available, the first consisting of energy-intensive medium-sized industrial companies' energy audits (lacking EEU data), the second consisting of SMEs from conducted energy audits in non-energy-intensive SMEs. The latter dataset had a sectoral breakdown of the electrical EEU, but not of the EEMs. The large heterogeneity among industrial SMEs together with the great diversity in the available national datasets seen in the data collection for this study calls for a common classification of EEU and EEMs in order to compare the data. 
Based on the literature review and the results and further analysis presented in this paper, it was concluded that there is no common way of categorizing industrial EEU data as well as EEMs for industrial SMEs in the studied countries, even though recent research has shown development in the categorization of EEMs (Fleiter et al., 2012; Trianni et al., 2014). As industrial SMEs represents more than $99 \%$ of all companies in the studied countries, this addresses the importance of further studies in creating a harmonized way of categorizing data. Moreover, reliable bottom-up data of EEU and EEMs is also scarce for industrial SMEs in the studied countries. The results of the study also showed that the energy efficiency potential was found to vary to a large extent depending on country-specific issues, different classifications of industrial sectors, and type of technology or process focused on. The largest energy efficiency potential in percent was found in the Italian dataset. This may be explained by factors such as that the data comes from audits conducted from a research group, and thus may have a higher quality due to the fact that the audits are done for research reasons, compared e.g. to data collected from the Belgium and Swedish energy audit programs, where the audits were done by technical consultants. For Sweden for example, no competence criteria was required for auditors to conduct energy audits with subsidy from the Swedish Energy Agency. Moreover, one more explanation why potential figures differ is that the dataset differs between Italy, Sweden and Belgium: the latter consisting of medium-sized energy-intensive companies, whereas the potential savings for different processes were not available for the first-line energy audit program.

The research methodology of this study had several limitations that need to be stated. In fact, it should be noted that, even though the data has been processed within the respective research groups, the quality of the data may contain errors on multiple levels. As for three of the countries, data was collected from energy audits, and these audits may have measurement errors. The same may also hold for the country (Japan) from which data was collected top- 
down, as the data originally has been derived from energy audits. Moreover, the way of categorizing data may also deviate from the respective country, e.g. pumping may for some energy auditors and industrial companies be seen as part of the support processes, and for some as part of the production processes, and for some, a distinction between support and production processes is not made. This makes comparisons between the datasets more difficult. Despite the fact that no general taxonomy exists, and the abovementioned limitations in the datasets, the EEU data from the dataset of industrial SMEs from Italy, Japan and Sweden shows that about half or more of the EEU is found in the production processes while results for the energy efficiency potential shows that it is in the non-production-related processes where the major energy efficiency potential is being spotted among industrial SMEs.

Thus, the non-homogeneous data have not allowed for further comparison between countries, processes or sectors. Here we can see the great relevance of promoting a common structure for gathering bottom-up information about EEU as well as energy efficiency potential. In fact, more homogenous information could lead to effective benchmarking activities that represent a basis for the promotion of the best actions at all policy-making levels, i.e., local, national or even international. A general taxonomy that could be applicable for industrial SMEs is also of great importance, in order to gain general knowledge on EEU and EEMs on national and international levels, to enable international comparisons, and to be able to conduct high quality research related to industrial SMEs. However, this type of taxonomy is not yet decided upon internationally, but this paper suggests a basis for such a general taxonomy, divided into production processes and support processes.

As illustrated in this paper the lack of taxonomy makes it difficult to draw general conclusions, not only from this study, but on industrial EEU and EEMs for industrial SMEs in general. The datasets from the studied countries presented in this paper, are to the author's awareness the most highly representative data that was publicly available in the studied coun- 
tries. As problems were encountered in finding data on industrial EEU and EEMs, it is most likely that policy-makers do not have access to this data either. This implies for example that stated energy efficiency potentials, from e.g. governmental organizations presented for the industrial sector, are, at best, qualitative expert estimations, and not based on real bottom-up data.

Without the development of such a general taxonomy, the deployment level of energy efficiency measures and carbon dioxide emission reductions is never likely to reach its full potential as knowledge is missing on how large the potential is, in which processes the major potential is found, how far industry has reached in terms of deployment levels, and in which areas future energy policies are needed.

To further stress improved energy efficiency from a policy perspective, the need for improved quantity and quality of such data cannot be understated, and calls for the development of a general taxonomy. Such taxonomy would create a harmonized view of where energy is used in industry, and moreover, show policy-makers where the major potential for energy efficiency improvements may be found. In light of this, this paper may be seen as one small step towards the creation of such a much-needed taxonomy enabling a harmonized way of categorizing data.

In conclusion, this paper concerning technical aspects of energy systems in industrial SMEs addresses the high importance of future research creating a harmonized data categorization, as this will greatly support the transition towards sustainable industrial energy systems.

\section{Acknowledgements}

The authors would warmly like to thank the respective national research organizations for financing this research project. Acknowledgement also to the Swedish Energy Agency for funding the Swedish management of the research project. Finally, the authors would also like 
to warmly thank the national bodies from where data has been achieved, and also the anonymous reviewers for their good inputs and constructive suggestions, that considerably improved the quality of the paper. The usual disclaimer holds.

\section{References}

Commissie Auditconvenant Vlaanderen, 2006. Annual report on the year 2005-2006

Commissie Auditconvenant Vlaanderen, 2007. Annual report on the period June 2006June 2007

Commissie Auditconvenant Vlaanderen, 2008. Annual report on the period June 2007May 2008

Cooremans, C., 2011. Investment in energy efficiency: Do the characteristics of investments matter? Energy Efficiency 5(4): 497-518.

Cornelis E., Reunes G., 2012. Analysis of the differences of the energy saving measures proposed by medium-sized industrial companies in Flanders, Belgium in 2006 and 2009. Proceedings of the ECEEE 2012 Summer Study on Energy Efficiency in Industry. Arnhem, 1114 September 2012.

Cornelis E., 2014. Lessons learnt from two long-term agreements on energy-efficiency in industry in Flanders, Belgium. Proceedings of the ECEEE Industrial Summer Study on Energy Efficiency in Industry, Arnhem, 2 - 5 June 2014.

EC (European Commission), 2003a. 2003/361/EG, Commission Recommendation of 6 May 2003 concerning the definition of micro, small and medium-sized enterprises.

EC (European Commission), 2006. Directive 2006/32/EC of the European Parliament and of the Council of 5 April 2006 on energy end-use efficiency and energy services and repealing Council Directive 93/76/EEC, Brussels.

EC (European Commission), 2007. Observatory of European SMEs. 
Energy Conservation Center Japan (ECCJ), 2011. Guidebook for energy conservation activity in industry 2011-2012.

European Council, 2012. Directive 2012/27/EU on energy efficiency, amending Directives 2009/125/EC and 2010/30/EU and repealing Directives 2004/8/EC and 2006/32/EC, Vol. 4.: $1-56$.

Fleiter, T., Hirzel, S., Worrell, E., 2012. The characteristics of energy-efficiency measures - a neglected dimension. Energy Policy 51: 5012-513.

Funk, P., Hardin, R. 2012. Cotton gin electrical energy use trends and 2009 audit results. Applied Engineering in Agriculture 28(4): 503-510.

IEA, 2013. World Energy Outlook 2013. Paris, France.

IEA, 2014. International Energy Agency, Capturing the Multiple Benefits of Energy Efficiency.

Kabir, G., Abubakar, A., El-Nafaty, U., 2010. Energy audit and conservation opportunities for pyroprocessing unit of a typical dry process cement plant. Energy 35: 1237-1243.

Kostka, G., Moslener, U., Andreas, J., 2013. Barriers to increasing energy efficiency: evidence from small and medium-sized enterprises in China. Journal of Cleaner Production 57(15): 59-68.

Land Brains, 2009. Survey on energy conservation activity in SMEs. Report to Ministry of Economy, Trade and Industry of Japan (METI). Land Brains Co., Ltd.

Lung, R. B., McKane, A., Leach R. and Marsh D., 2005. Ancillary savings and production benefits in the evaluation of industrial energy efficiency measures. Proceedings ACEEE Summer Study on Energy Efficiency in Industry.

Mills, E. and Rosenfeld, A., 1996. Consumer non-energy benefits as a motivation for making energy-efficiency improvements. Energy 21(7-8): 707-720. 
Ministry of Economy, Trade and Industry of Japan (METI), 2011. Guide for making an action plan for saving electricity.

Muller, M., Kasten, D., 2007. Industrial Assessment Center. Assessment Recommendation Code (ARC). Rutgers University.

Pye, M. and McKane, A., 2000. Making a stronger case for industrial energy efficiency by quantifying non-energy benefits. Resources, Conservation and Recycling 28(3-4): 171-183.

Rohdin, P., Thollander, P., and Solding, P., 2007. Barriers to and drivers for energy efficiency in the Swedish foundry industry. Energy Policy 35 (1), 672-677.

Salva, M., Jones, S., Marshall, R., Bishop, C., 2013. An audit tool for environmental measurement in the UK food sector. International Journal of Food Science and Technology 48: $1509-1518$.

Sardianou, E., 2008. Barriers to industrial energy efficiency investments in Greece. Journal of Cleaner Production 16 (13): 1416-1423.

Schleich, J., Gruber, E., 2008. Beyond case studies: Barriers to energy efficiency in commerce and the services sector. Energy Economics 30 (2): 449-464.

Shipley, A. (2001). Energy efficiency programs for small and medium-sized industry. ACEEE Summer Study: 183-196.

Söderström, M., 1996. Industrial Electricity Use Characterized by Unit Processes. A Tool for Analysis and Forecasting. Proc. UIE XIII Congress on Electricity Applications, Birmingham: 77-85.

Thollander P, Karlsson, M Söderström M, Creutz D, 2005. Reducing industrial energy costs through energy efficiency measures in a liberalized European electricity market - case study of a Swedish iron foundry. Applied Energy 81(2): 115-26. 
Thollander P., Danestig M., Rhodin P., 2007. Energy policies for increased industrial energy efficiency: evaluation of a local energy programme for manufacturing SMEs. Linköping University, Linköping.

Thollander P, Rohdin P, Moshfegh B, 2012. On the formation of energy policies towards 2020: challenges in the Swedish industrial and building sectors. Energy Policy 42: 461-467.

Thollander P., Karlsson, M., Rohdin, P., Söderström, M., Rosenqvist, J., 2012. A standardized energy audit tool for improved energy efficiency in industrial SMEs. Linköping University, Linköping.

Thollander, P., Cornelis, E., Kimura, O., Morales, I., Zubizarreta Jiménez, R., Backlund, S., Karlsson, M., Söderström, M., 2014. The design and structure of effective energy end-use policies and programs towards industrial SMEs. ECEEE Industrial Summer Study, Arnhem.

Tokyo Metropolitan Government, 2007, Energy saving measures in noodle factories. Available at: http://www.tokyo-co2down.jp/ecology/save.

Tokyo Metropolitan Government, 2008a, Energy saving measures in fur glossing factories. Available at: http://www.tokyo-co2down.jp/ecology/save.

Tokyo Metropolitan Government, 2008b, Energy saving measures in metal coating factories. Available at: http://www.tokyo-co2down.jp/ecology/save.

Tokyo Metropolitan Government, 2012, Energy saving measures in confectionery factories. Available at: http://www.tokyo-co2down.jp/ecology/save.

Trianni, A., Cagno, E., 2012. Dealing with barriers to energy efficiency and SMEs: Some empirical evidences. Energy 37(1): 494-504.

Trianni, A., Cagno, E., Donatis, A., 2014. A framework to characterize energy efficiency measures. Applied Energy 118: 207-220.

Trygg L., Karlsson B. 2005. Industrial DSM in a deregulated European electricity market a case study of 11 plants in Sweden. Linköping University, Linköping. 
United Nations Statistics Division, 2008. International Standard Industrial Classification of All Economic Activities (ISIC), Rev. 4. Department of Economic and Social Affairs, Statistics Division. United Nations, New York.

Westling, H., 2000. Annex III. FINAL MANAGEMENT REPORT. Co-operative Procurement of Innovative Technologies for Demand-Side Management. Download at: http://www.ieadsm.org/Files/Tasks/Task\%203\%20-\%20Cooperative $\% 20$ Procurement $\% 20$ of $\% 20$ Innovative $\% 20$ Technologies $\% 20$ for $\% 20$ DemandSide\%20Management/General\%20Information/FRpt.pdf

Worrell, E., Laitner, J. A., Ruth, M. and Finman, H., 2003. Productivity benefits of industrial energy efficiency measures. Energy 28(11): 1081-1098.

Yingjiana, L., Jiezhi, L., Qi, Q., Yafei, X., 2010. Energy auditing and energy conservation potential for glass works. Applied Energy 87: 2438-2446. 